This is the final peer-reviewed accepted manuscript of

Hassan, Marwan A.; Bird, Stephen; Reid, David; Ferrer-Boix, Carles; Hogan, Dan; Brardinoni, Francesco;

Chartrand, Shawn: Variable hillslope-channel coupling and channel characteristics of forested mountain streams in glaciated landscapes. EARTH SURFACE PROCESSES AND LANDFORMS 44. ISSN 0197-9337

DOI: $10.1002 /$ esp.4527

The final published version is available online at: $\underline{\text { http://dx.doi.org/10.1002/esp.4527 }}$

Rights / License: The terms and conditions for the reuse of this version of the manuscript are specified in the publishing policy. For all terms of use and more information see the publisher's website. 


\title{
Variable hillslope-channel coupling and channel characteristics of forested mountain streams in glaciated landscapes
}

\author{
Marwan A. Hassan, ${ }^{1 *}$ Stephen Bird, ${ }^{2}$ David Reid, ${ }^{1}$ Carles Ferrer-Boix, ${ }^{3} \quad$ Dan Hogan, ${ }^{1}$ Francesco Brardinoni ${ }^{4}$ and Shawn \\ Chartrand \\ ${ }^{1}$ Department of Geography, The University of British Columbia, Vancouver, BC Canada, V6T 1 Z2 \\ 2 Fluvial Systems Research Inc., 50115216 North Bluff Road, White Rock, BC Canada, V4B OA7 \\ 3 Department of Civil and Environmental Engineering, Technical University of Catalonia, Barcelona, Spain \\ ${ }^{4}$ Department of Biological, Geological and Environmental Sciences (BiGeA), University of Bologna, 40126 Bologna, Italy
}

*Correspondence to: Marwan A. Hassan, Department of Geography, The University of British Columbia, Vancouver, BC, Canada, V6T 1Z2. E-mail: marwan hassan@geog.ubc.ca

\begin{abstract}
Channel morphology of forested, mountain streams in glaciated landscapes is regulated by a complex suite of processes, and remains difficult to predict. Here, we analyze models of channel geometry against a comprehensive field dataset col lected in two previously glaciated basins in Haida Gwaii, B.C., to explore the influence of variable hillslope channel coupling imposed by the glacial legacy on channel form. Our objective is to better understand the relation between hillslope channel cou pling and stream character within glaciated basins. We find that the glacial legacy on landscape structure is characterized by rela tively large spatial variation in hillslope channel coupling. Spatial differences in coupling influence the frequency and magnitude of coarse sediment and woody material delivery to the channel network. Analyses using a model for channel gradient and multiple models for width and depth show that hillslope channel coupling and high wood loading induce deviations from standard down stream predictions for all three variables in the study basins. Examination of model residuals using Boosted Regression Trees and nine additional channel variables indicates that $\sim 10$ to $\sim 40 \%$ of residual variance can be explained by logjam variables, $1540 \%$ by the degree of hillslope channel coupling, and $1020 \%$ by proximity to slope failures. These results indicate that channel classification systems incorporating hillslope channel coupling, and, indirectly, the catchment glacial legacy, may present a more complete un derstanding of mountain channels. From these results, we propose a conceptual framework which describes the linkages between landscape history, hillslope channel coupling, and channel form.
\end{abstract}

KEYWORDS: mountain streams; hillslope channel coupling; hydraulic geometry; wood; landslides; process domains; channel classification; divide breaching; glacial history

\section{Introduction}

Channel morphology and typology derive primarily from the local interplay between sediment supply and channel transport capacity (Schumm, 1977). In forested mountain environments, sediment and wood supply is dominated by landslide and debris flow inputs originating from adjacent hillslopes and steep colluvial tributaries (Nakamura and Swanson, 1993; Grant and Swanson, 1995; Benda and Dunne, 1997a, 1997b; Benda and Sias, 2003; May and Gresswell, 2003; Rigon et al., 2012; Hassan et al., 2016). In such settings, fluvial sys tems characterized by simple concave up longitudinal profiles typically exhibit hillslope channel sediment connectivity (i.e. Bracken et al., 2015, hereafter termed hillslope channel connectivity) that declines progressively downstream from the headwaters as channel slope decreases and valley width increases (Wohl, 2017). An idealized progression of channel types in these systems would include strongly coupled debris flow dominated channels at the headwaters followed by transitional (partially coupled) channels where debris flow disturbance (mainly deposition) coexists with fluvial reworking, and finally (uncoupled) fluvially dominated channels further downstream (Montgomery and Buffington, 1997; Church, 2002; Gomi et al., 2002; Brummer and Montgomery, 2003). Along the fluvial portions of concave up longitudinal profiles, a schematic sequence of channel morphologies may be observed as a function of decreasing channel slope and increas ing contributing area, starting from coarsely bedded and poorly organized morphologies (e.g. boulder cascade) down to finer textured and organized (e.g. riffle pool) reaches (Montgomery and Buffington, 1997). In these reaches, channel cross sectional variables (geometry) are assumed to be well described as functions of local slope, grain size, and stream discharge (Leopold and Maddock, 1953; Ferguson, 1986; Wohl, 2004; Finnegan et al., 2005; Parker et al., 2007).

Peculiar geomorphic contexts resulting from the interplay between dependent and independent river variables in time and space (Schumm and Litchy, 1965) can display diverse 
arrangements of forms and processes along river networks (Wohl, 2018). In landscapes with a history of intense glaciation (Brardinoni and Hassan, 2006, 2007) hillslope channel connectivity may become more spatially complex and therefore may depart from a predictable downstream pattern of progressive weakening. The case of glacial conditioning is particularly critical, since formerly glaciated and currently glacierized orogens represent a large proportion of terrestrial mountain settings. However, they have received limited attention, and consequently our understanding of the downstream patterns of channel bed texture and geometry in steep glaciated settings remains elusive.

Glacial conditioning of hillslope channel connectivity may arise from a combination of factors including comparably wider and deeper valleys (Montgomery, 2002), altered basin hypsometry (Brocklehurst and Whipple, 2004), stepped longitudinal profiles alternating between coupled and uncoupled valley segments (Brardinoni and Hassan, 2006), and hillslopes mantled by unstable surficial materials such as till and glaciolacustrine deposits (Slaymaker, 1993; Brardinoni et al., 2003).

Channel networks with complex spatial configurations of hillslope channel connectivity pose major challenges for understanding and predicting downstream patterns of channel geometry, morphology and bed texture. A limited number of approaches have been proposed to incorporate the influence of hillslope channel connectivity, as modulated by landscape structure, into current knowledge of what controls stream channel form and dynamics at finer scales. For example, Whiting and Bradley (1993) propose a channel classification scheme that describes reaches based on their likelihood of receiving landslide and debris flow sediment supply. This scheme uses the ratio of non channel floodplain width to the average maximum runout length of slope failures to provide a probabilistic estimate of hillslope channel connectivity, and therefore describes the potential degree of coupling at any point along a network, regardless of landscape history. Grant and Swanson (1995) examine post flood spatial patterns of channel erosion and deposition in two unglaciated mountain streams of western Oregon. They explain observed channel changes with nonfluvial disturbance as modulated by the spatial configuration of landforms (e.g. fans and terraces) and sediment sources (e.g. landslides and debris flows), hence proposing a scheme for discriminating channel response potential in relation to slope and a valley floor width index (i.e. valley floor width to active channel width ratio).

Brummer and Montgomery (2003) examine downstream sequences of surface and subsurface particle size in relation to three broadly defined geomorphic process domains described above, including: debris flow dominated, transitional, and fluvial channels in four partially glaciated basins in Washington State. In another case study in California, Brummer and Montgomery (2006) provide examples of how hillslope sediment inputs, can locally influence particle size by introducing sediment too coarse to be fluvially mobilized. Using a combi nation of field and remotely sensed data from heavily glaciated terrain in southwestern British Columbia, Brardinoni and Hassan (2007) show that channel reach morphology is strongly controlled by glacially imposed channel slope and degree of hillslope channel connectivity. More recently, in partially glaciated basins of the Colorado Front Range, Livers and Wohl (2015) found that characteristics of (upstream) glaciated headwater reaches differed substantially from (downstream) unglaciated analogs, partly as a result of imposed valley bottom confinement.

While these approaches have made valuable contributions towards identifying and classifying scale linkages between large scale landscape structures and in stream features, a comprehensive understanding of possible dependencies cascading from landscape organization down to hillslopechannel connectivity and in stream variables is still missing. Of particular interest are the causal linkages between glacial inheritance and in stream quantitative variables such as width, depth, and particle size. In addition, the role of wood load in relation to hillslope channel connectivity needs to be investigated explicitly, as it may greatly influence channel form in glaciated mountain streams. In summary, the effect of the spatial organization of wood and sediment delivery from hillslopes and their connection to landscape history and channel variables remains an open question.

To this purpose, we propose the following conceptual framework: finer scale channel variables such as width, depth, and local slope are controlled not only by discharge, local particle size, and valley slope, but also by a cascade of processes linking these variables to channel coupling, and in turn to landscape history. From this framework, we hypothesize that variability in channel geometry (width, depth, slope) and particle size is a function not only of local flow conditions and texture of sediment transported from upstream or eroded locally, but also of the variability in sediment and wood sources and delivery processes inherent to highly coupled landscapes.

In order to evaluate our proposed concept and test the hypothesis, we examine downstream patterns of channel characteristics in relation to mass wasting driven sediment and wood inputs in (formerly) glaciated basins with variable hillslopechannel connectivity, focusing on sediment texture and downstream hydraulic geometry (i.e. channel width, slope and depth). Our specific objectives are to: (1) describe downstream patterns in sediment texture and channel geomorphological characteristics in two glaciated mountain basins; and (2) evaluate possible causal linkages between observed spatial patterns and the degree of hillslope channel connectivity and assess the importance of landscape and coupling variables on channel geometry.

Our work focuses on two volcanic mountain streams in Haida Gwaii, British Columbia, which were repeatedly overridden by Pleistocene advances of the Queen Charlotte Islands Ice Sheet (Sutherland Brown, 1968). The datasets for these basins are unique; channel geometry, morphology, particle size and in stream wood data are present over a combined $21 \mathrm{~km}$ of stream channel, in addition to a detailed landslide inventory covering both basins. For both catchments, we integrate field data, topographic analysis, hydraulic geometry modeling and statistical evaluation of model output to directly demonstrate the effect of landscape connectivity and logjams on these variables.

\section{Study watersheds}

The study was conducted in Gregory and Riley creeks, two adjacent mountain basins located in the Graham Ranges (Skidegate Plateau), west of the archipelago divide in Haida Gwaii, British Columbia, Canada (Figure 1). The area was overridden by the Queen Charlotte Islands Ice Sheet during Fraser glaciation, resulting in the glacial carving of bedrock troughs and in the deposition of till that blankets most of the mid to lower elevation slopes (Alley and Thompson, 1978). Ice masses flowed outward to the eastern and western coastlines from the main archipelago divide, with only a limited number of outstanding nunataks (Sutherland Brown, 1968).

West of the divide, intense glacial erosion on relatively weak volcanic lithology has generated: (i) glacial troughs dominantly aligned east to west (i.e. the relict axes of the main ice flows), which today host the main fluvial valley floors; (ii) widespread 


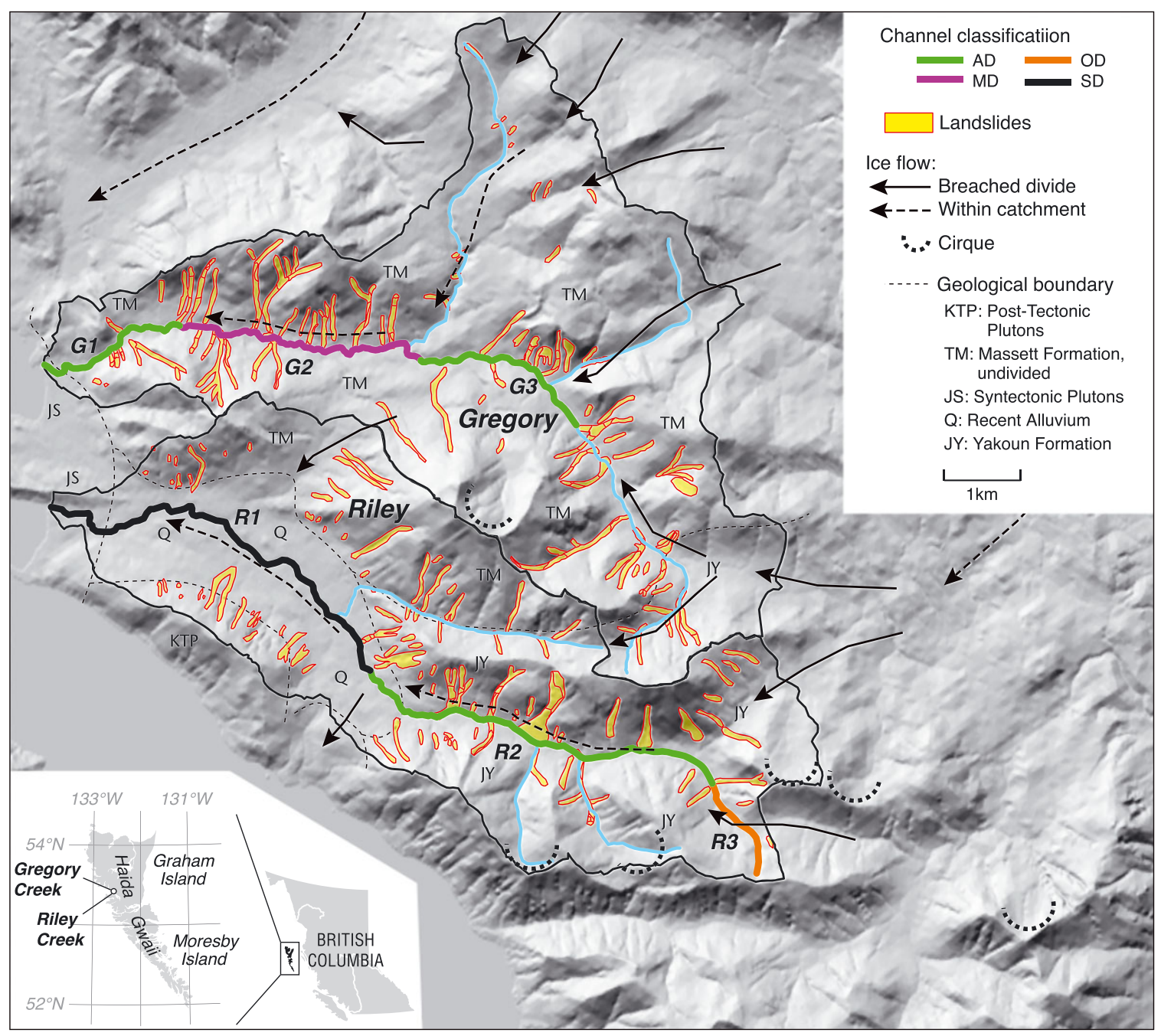

Figure 1. Location map, watersheds, geology, landslides, glacial history and study reaches of Riley and Gregory creeks. Reaches are delineated based on criteria outlined in Whiting and Bradley (1993): (SD debris flows seldom enter the channel (probability of entry < 10\%); OD occasional debris flows enter the channel (10 50\%); MD debris flow frequently enter the channel (50 $100 \%$ ); and AD debris flows certainly enter the channel $(100 \%)$. Ice flow direction is indicated by solid (flow is within a catchment) and dashed (ice flow crosses catchment divide) lines with arrows. [Colour figure can be viewed at wileyonlinelibrary.com]

divide breaching (i.e. oriented dominantly northeast to southwest) that cut across adjacent basins due to past glacial transfluence; and (iii) a limited number of hanging cirques on tributary valleys, dominantly facing north (Figure 1).

The two basins are similar in terms of drainage basin area $\left(A_{d}\right)$, terrain, and precipitation regime, with mean annual precipitation exceeding $3600 \mathrm{~mm}$ and mostly falling as rain (Williams, 1968). Gregory Creek is mainly underlain by the Massett Formation composed of basalt and rhyolite ash flows of volcanic origin (Sutherland Brown, 1968). Basin headwaters ( 10\% of total area) are underlain by part of the Yakoun formation, composed of paraphytic andesite agglomerate and flows, and some volcanic sandstone. By comparison, the geology of Riley Creek is more diverse, underlain by the Yakoun Formation in the eastern part, and covered by a thick blanket of glacial deposits at low elevations to the west. To the north of the broad valley bottom lies part of the Massett formation, and to the south, a small pluton formed of quartz and granite. The mainstem stream channels possess similar riffle pool morphologies and high wood loads. General characteristics of the study reaches are summarized in Table I.

Mass wasting activity is widespread, and associated with storms that produce precipitation in excess of $120 \mathrm{~mm} / 12 \mathrm{~h}$ (Wilford and Schwab, 1982), weak and highly fractured lithology, and seismic activity (Gimbarzevsky, 1988; Martin et al.,
Table I. Summary characteristics of study reaches in Riley and Gregory Creeks

\begin{tabular}{lccccc}
\hline Reach & $\begin{array}{c}\text { Reach } \\
\text { length }(\mathrm{m})\end{array}$ & $\begin{array}{c}\text { Channel } \\
\text { Classification* }\end{array}$ & $\mathrm{B}(\mathrm{m})$ & $\mathrm{H}(\mathrm{m})$ & $\mathrm{S}(\mathrm{m} / \mathrm{m})$ \\
\hline Riley & & $\mathrm{ND}$ & 24.7 & 1.83 & 0.009 \\
R1 & 5935 & $\mathrm{SD}$ & 19.1 & 1.61 & 0.023 \\
R2 & 5266 & $\mathrm{AD}$ & 19.7 & 1.08 & 0.013 \\
R3 & 1005 & $\mathrm{OD}$ & & & \\
Gregory & & & & & \\
G1 & 2211 & AD & 30.4 & 1.88 & 0.011 \\
G2 & 3655 & MD & 31.9 & 2.05 & 0.012 \\
G3 & 2687 & AD & 15.5 & 1.48 & 0.020 \\
\hline
\end{tabular}

*Channel classification described by Whiting and Bradley (1993).

B bankfull channel width; $\mathrm{H}$ bankfull depth and $\mathrm{S}$ channel slope. Data were collected by the British Columbia Ministry of Forests. See Table S1 for additional details on measurements.

2002). The inherent instability of the hillslopes has been increased locally by logging (Gimbarzevsky, 1988; Martin et al., 2002). At the time of survey, approximately $2 \%$ and $12 \%$ of the basin area of Gregory and Riley creeks, respectively, were logged, primarily in the mid to late 1970s (Hogan et al., 1998). A large number of slope failures have been initiated along roads either in badly placed side casts or above truncated spurs. 
A summary of within channel stored Large Wood (LW) and sediment characteristics, volume of sediment delivered from landslides, sediment stored behind logjams, and the number of debris flow prone tributaries for Gregory and Riley creek reaches is given in Figure 2(a) and 2(b), and in Table II. Additional detailed information about wood sources and characteristics can be found in Hassan et al. (2016). Overall, we identified 52 and 106 logjams in Gregory and Riley creeks, respectively. Logjam age ranged from a few years and up to 95 with a mean age of 50 years and 40 years for Gregory and Riley creeks, respectively (Hassan et al., 2016).

\section{Field data collection}

In the summers of 1988 and 1989, technicians and researchers with the British Columbia Ministry of Forests conducted extensive surveys to characterize channel morphology in Riley and Gregory creeks (Hogan et al., 1998; Hassan et al., 2016). During the same period, interpretation of aerial imagery for landslide characterization was conducted. Channel surveys were carried out over longitudinal profile lengths of $8.56 \mathrm{~km}$ and $12.21 \mathrm{~km}$ in Gregory and Riley creek, respectively. The survey captured channel geometry, including bankfull depth $(H)$, bankfull width $(B)$, channel slope $(S)$, within channel sediment storage and texture $D_{95}$ and $D_{50}$, where the $D_{50}$ data were collected by Steve Rice (reported in Rice, 1995), in channel wood characteristics (e.g. volume of wood and sediment, age, etc.), and landslides (volumes of sediment and wood input into channels, location of entry points, and age). Measurements of $H, S$, and $D_{95}$ were made at intervals based on a single average channel width, while $B$ was measured at an interval of every fifth width. Morphological features, such as pools, riffles, and steps were measured at supplementary survey points. As indicated in Table S1, most data were collected at intervals of one bankfull channel width. For summary of channel metrics and additional measurement information see Table SI in the supporting material.

\section{Methods and analyses}

\section{Hillslope-channel coupling}

To classify channel reaches and evaluate hillslope sediment delivery to streams across the drainage basin components, we used the topography based geomorphic process domains and hillslope channel coupling frameworks, as defined by Montgomery and Foufoula Georgiou (1993), Whiting and Bradley (1993), Brummer and Montgomery (2003) and Brardinoni and Hassan (2006). This analysis addresses our second objective, and was accomplished using GIS topographic analysis,

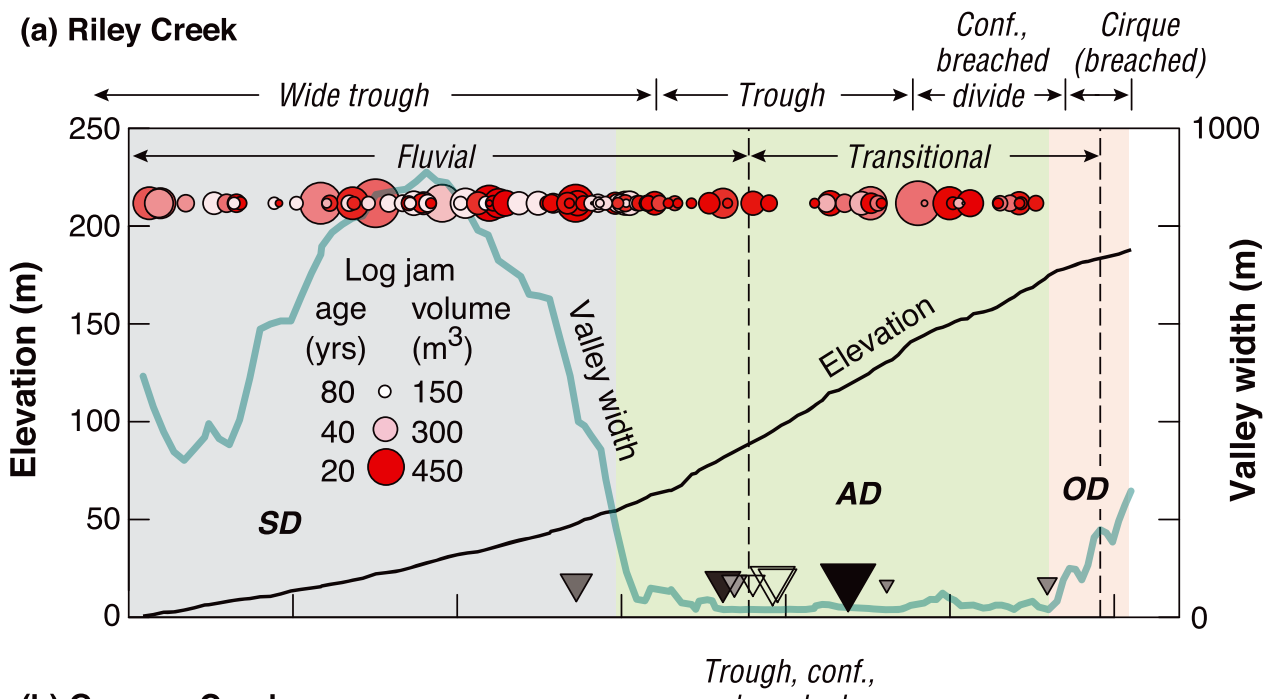

(b) Gregory Creek

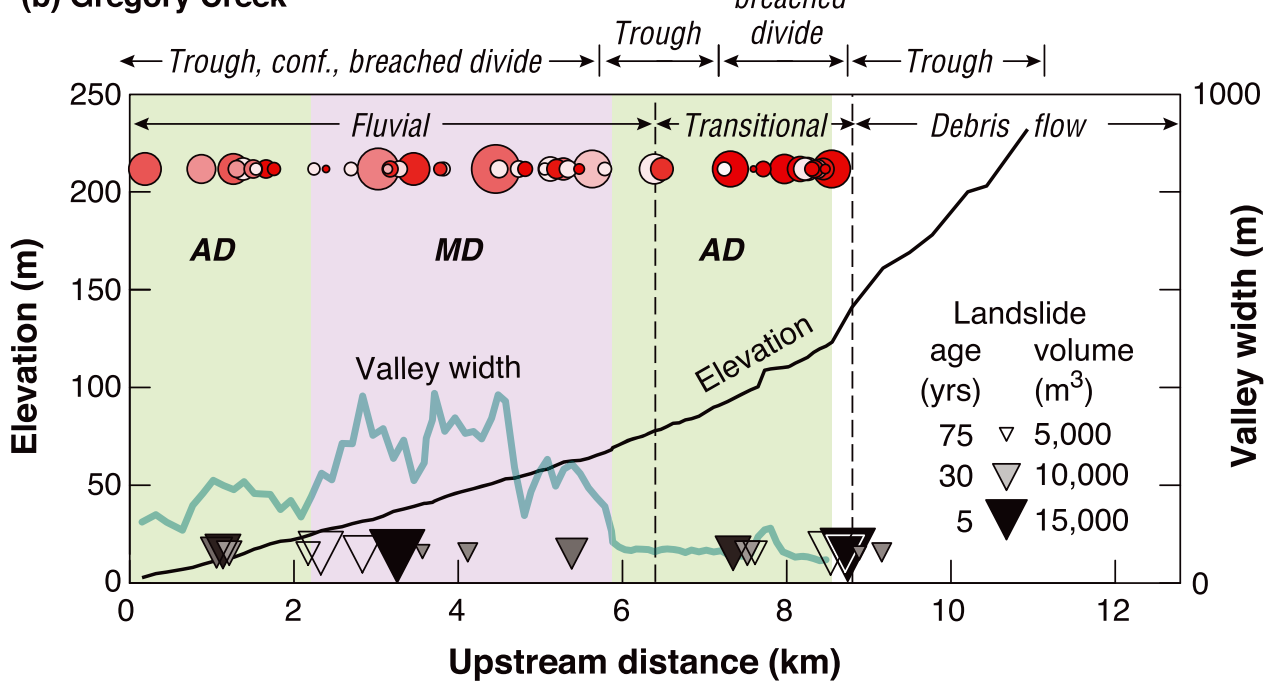

Figure 2. Longitudinal profiles, valley width, landslides (location, age, volume of sediment), logjams (location, age and volume of wood), and glacial landforms. Brummer and Montgomery (2003) process domains (debris flow, transition, fluvial) and Whiting and Bradley (1993) are shown. Note that for logjams and landslides, symbol size corresponds to volume, and shading to age. [Colour figure can be viewed at wileyonlinelibrary.com] 
Table II. Characteristics of wood, sediment storage, and hillslope sediment delivery in Riley and Gregory Creeks

\begin{tabular}{|c|c|c|c|c|c|c|c|c|c|}
\hline Reach & $\begin{array}{l}\text { Number } \\
\text { of jams }\end{array}$ & $\begin{array}{c}\text { Jam } \\
\text { spacing (m) }\end{array}$ & $\begin{array}{l}\text { Mean jam } \\
\text { age (year) }\end{array}$ & $\begin{array}{l}\text { Jam LW } \\
\text { storage } \\
\left(\mathrm{m}^{3} \mathrm{~km}^{1}\right)\end{array}$ & $\begin{array}{l}\text { Sediment stored } \\
\text { by jams } \\
\left(10^{3} \mathrm{~m}^{3} \mathrm{~km}^{1}\right)^{\mathrm{a}}\end{array}$ & $\begin{array}{l}\text { Total stored } \\
\text { sediment } \\
\left(10^{3} \mathrm{~m}^{3} \mathrm{~km}^{1}\right)^{\mathrm{b}}\end{array}$ & $\begin{array}{l}\text { Number of } \\
\text { slides reaching } \\
\text { channel }\end{array}$ & $\begin{array}{l}\text { Number of } \\
\text { torrented } \\
\text { tributaries }\end{array}$ & $\begin{array}{c}\text { Sediment delivered } \\
\text { from slides } \\
\left(10^{3} \mathrm{~m}^{3} \mathrm{~km}^{1} \mathrm{yr}^{1}\right)^{\mathrm{c}}\end{array}$ \\
\hline R1 & 57 & 104.1 & 56 & 1100.4 & 13.2 & 81.9 & 0 & 3 & 0.000 \\
\hline R2 & 46 & 114.5 & 39 & 754.7 & 5.7 & 64.4 & 7 & 10 & 0.065 \\
\hline R3 & 0 & & & 0.0 & 0.0 & 66.3 & 0 & 0 & 0.000 \\
\hline G1 & 9 & 245.7 & 52 & 644.5 & 6.0 & 91.4 & 4 & 2 & 0.075 \\
\hline G2 & 22 & 166.1 & 51 & 906.8 & 20.3 & 91.2 & 7 & 7 & 0.157 \\
\hline G3 & 16 & 167.9 & 61 & 580.2 & 8.6 & 57.2 & 8 & 5 & 0.136 \\
\hline
\end{tabular}

ancludes sediment stored in bars and material stored above bedrock. Does not include floodplain storage.

${ }^{\mathrm{b}}$ Calculated from channel geometry data adjacent to jam.

${ }^{\mathrm{c}}$ Only includes delivery from slope failures which deposited sediment in the main channel.

fieldwork, and aerial photo interpretation. We adopted the Brummer and Montgomery (2003) geomorphic domain boundaries to identify debris flow (i.e. colluvial channels), transitional, and fluvially governed corridor settings. We choose to focus on the Brummer and Montgomery (2003), and Whiting and Bradley (1993) domain classifications, as they all explicitly consider hillslope sediment delivery potential to streams but through different approaches. Whiting and Bradley (1993) describe a process based approach to define linkages at the scale of landscape building blocks including individual hillslopes and channel segments, independently of the broader catchment configuration. Brummer and Montgomery (2003) apply a general framework describing hierarchical downstream processes at the catchment scale in relation to channel slope, contributing area, and stream power. In the context of formerly glaciated mountain basins, Brardinoni and Hassan (2006) introduce the concept of glacial inheritance by considering the influence of glacial macroforms (e.g. troughs, cirques and hanging valleys) on hillslope sediment input potential to headwater channels, and in turn to the configuration and arrangement of different channel morphologies.

We applied the Whiting and Bradley (1993) process based classification to separate channel reaches based on their proximity to steep hillslopes, resulting in the identification of three reaches each for Gregory and Riley creeks. Whiting and Bradley (1993) specifically suggested four coupling categories describing the probability of a slope failure entering an adjacent channel (see their Figure 1 Panel 2): SD debris flows seldom enter the channel (probability of entry $<10 \%$ ); OD occasional debris flows enter the channel (10 50\%); MD debris flows frequently enter the channel (50 100\%); and $A D$ debris flows certainly enter the channel (100\%). The probabilities are based on the ratio of average slope failure runout length to floodplain or valley bottom width. To apply this classification in our channels, we measured the valley and channel widths at intervals of five average channel widths for both creeks in the field, except for the lower part of Riley Creek (R1). In lower Riley Creek, the active valley bottom is recessed in a much larger valley and therefore the valley width was assessed remotely.

\section{Channel characteristics}

To evaluate the downstream changes in the channel characteristics in relation to reach classification and expected trends, we explore changes in $B, H, S$, and $D_{95}$ and $D_{50}$ of the bed surface. This analysis of channel characteristics addresses objective 1.
For $B$ we compared field measurements with three models: (1) Ferrer Boix et al. (2016); (2) Finnegan et al. (2005), and (3) Parker et al. (2007) hereafter referred to as the Ferrer Boix, Finnegan (gravel or boulder), and Parker width models, respectively. For the Finnegan model we provide a solution for both gravel and boulder beds. We note that even though the Finnegan model was developed for bedrock channels, it can provide insight regarding channel width expression in systems with beds composed of coarse, non fluvially sourced material (e.g. from mass movement, see Brummer et al. (2006)). In addition, we used Finnegan et al. (2005) and Parker et al. (2007) to estimate $H$, and Parker et al. (2007) to estimate $S$, hereafter referred to as the Finnegan (gravel or boulder) depth model, Parker depth model, and Parker slope model, respectively. For more details on the models, see Supporting information Text S1.

\section{Analysis of model residuals}

To provide an explanation for the observed variability in $B, H$ and $S$, we undertook a statistical analysis of residuals from the various $B, H$ and $S$ models using channel characteristics (see list below) not included in the three models of the section 'Channel characteristics'. We used boosted regression trees (BRT) (Hastie et al., 2009 and James et al., 2013) to predict the residuals associated with each model following the approach of Elith et al. (2008) and Hijmans et al. (2017). Residuals were calculated as a field measured value subtracted from the modeled value, meaning that a positive residual indicates an over prediction by the model (for more details on residual anal ysis, see Supporting information Text S1).

We used both categorical and numeric predictor variables in the BRT analysis. These include: (i) proximity to the nearest landslide that entered the channel (either upstream or downstream); (ii) volume of wood and sediment delivered to the channel by the nearest landslide; (iii) age of the nearest landslide; proximity to the nearest logjam (either upstream or downstream); (iv) volume of wood and sediment stored in the nearest logjam; age of the nearest logjam; (v) the Whiting and Bradley (1993) classification; (vi) basin area $\left(A_{\mathrm{d}}\right)$; and (vii) the basin it self (i.e. Gregory, Riley). Variables were selected to capture the effect of hillslope channel coupling on channel morphology (especially on channel width, depth and slope) at the channel unit scale (e.g. due to landslide input of sediment and local storage in logjams), the reach scale (Whiting and Bradley, 1993 classes), and the basin scale (e.g. influence of basin morphometry and geology). 


\section{Results}

\section{Landscape organization and hillslope-channel coupling}

The quantity of solid material input from hillslopes and the degree of hillslope channel coupling do not reduce consistently downstream, ranging from high within narrow troughs (AD reaches), to low in valley bottom buffered sections (SD) or in valley segments where adjacent hillslopes are not steep enough to sustain mass wasting activity (Figure 2).

The lowermost reach of Riley Creek (R1) flows through a wide trough floor, characterized by gentle valley sides due to glacial breaching of the divide to the north and south. This to pographic configuration disconnects all but one landslide event from the main channel, and results in a SD reach classification according to Whiting and Bradley (1993) (Figure 1 and 2(a)). Moving upstream, the valley becomes narrower and is bound by steep sided walls, resulting in a relatively high level of coupling (AD) in reach R2. In R2, this classification matches well with the large number of inventoried slope failures that delivered sediment and wood to the channel (Figures 1 and 2(a)). At the upstream limit of R2, however, the valley widens again, mainly due to glacial breaching from the northeast. The headwaters of Riley Creek (R3) are characterized by ill defined drainage divides, especially to the eastern and southeastern side, where the area exhibits a plateau like topography. Several slope failures nearly intersect the channel in this reach, but none has delivered sediment directly, and therefore the reach is classified as OD.

Along Gregory Creek, relict glacial macroforms tend to impose a different sequence of hillslope channel coupling conditions (Figures 1 and 2(b)). The valley is relatively narrow along much of its length, and overall the degree of interaction between the hillslope and the channel was medium to high, with reaches $G 1, G 2$, and $G 3$ classified as $A D, M D$, and $A D$, respectively. Figures 1 and 2(b) show that many landslides entered or nearly entered Gregory Creek along much of its length. Overall, the Whiting and Bradley (1993) classification corresponds well with observed hillslope sediment inputs delivered to the study streams, and depict two contrasting downstream sequences of channel types.

\section{Sediment texture}

The channel bed of the upper headwaters in Riley Creek $\left(A_{d}<\right.$ $0.3 \mathrm{~km}^{2}$ ) is dominated by large lag sediment originating from mainly steep tributaries. Although few surveyed points were available for $A_{d}<12 \mathrm{~km}^{2}$, we observe a fining trend in the $\mathrm{D}_{95}$ is in this region, extending down to approximately $A D$ $1 \mathrm{~km}^{2}$. For $A_{d}>12 \mathrm{~km}^{2}$, we note a systematic increase in the $D_{95}$ of the bed surface material with drainage area, with a peak at about $10 \mathrm{~km}^{2}$ and a subsequent decline down to $20 \mathrm{~km}^{2}$ (Figure 3(a)). Shifts in $\mathrm{D}_{95}$ are associated with transitions from $\mathrm{OD}$ to $\mathrm{AD}$ and from $\mathrm{AD}$ to $\mathrm{SD}$, suggesting strong hillslope influence in local sediment texture. These shifts in $\mathrm{D}_{95}$ also align well with the Brummer and Montgomery (2003) process domain breaks, though our data do not correspond as closely to their conceptual diagram of downstream changes in sediment texture (Figure 3(a)). Limited surface $D_{50}$ data are available from Rice $(1994,1995)$, collected from pebble counts and photographs. In Riley Creek, trends in $\mathrm{D}_{50}$ roughly mimic those in $\mathrm{D}_{95}$ for the channel sections where $\mathrm{D}_{50}$ data are available $\left(A_{d}>5 \mathrm{~km}^{2}\right)$. Surface texture clearly fines for $A_{d}>10 \mathrm{~km}^{2}$, in agreement with transitions from $\mathrm{AD}$ to $\mathrm{SD}$.
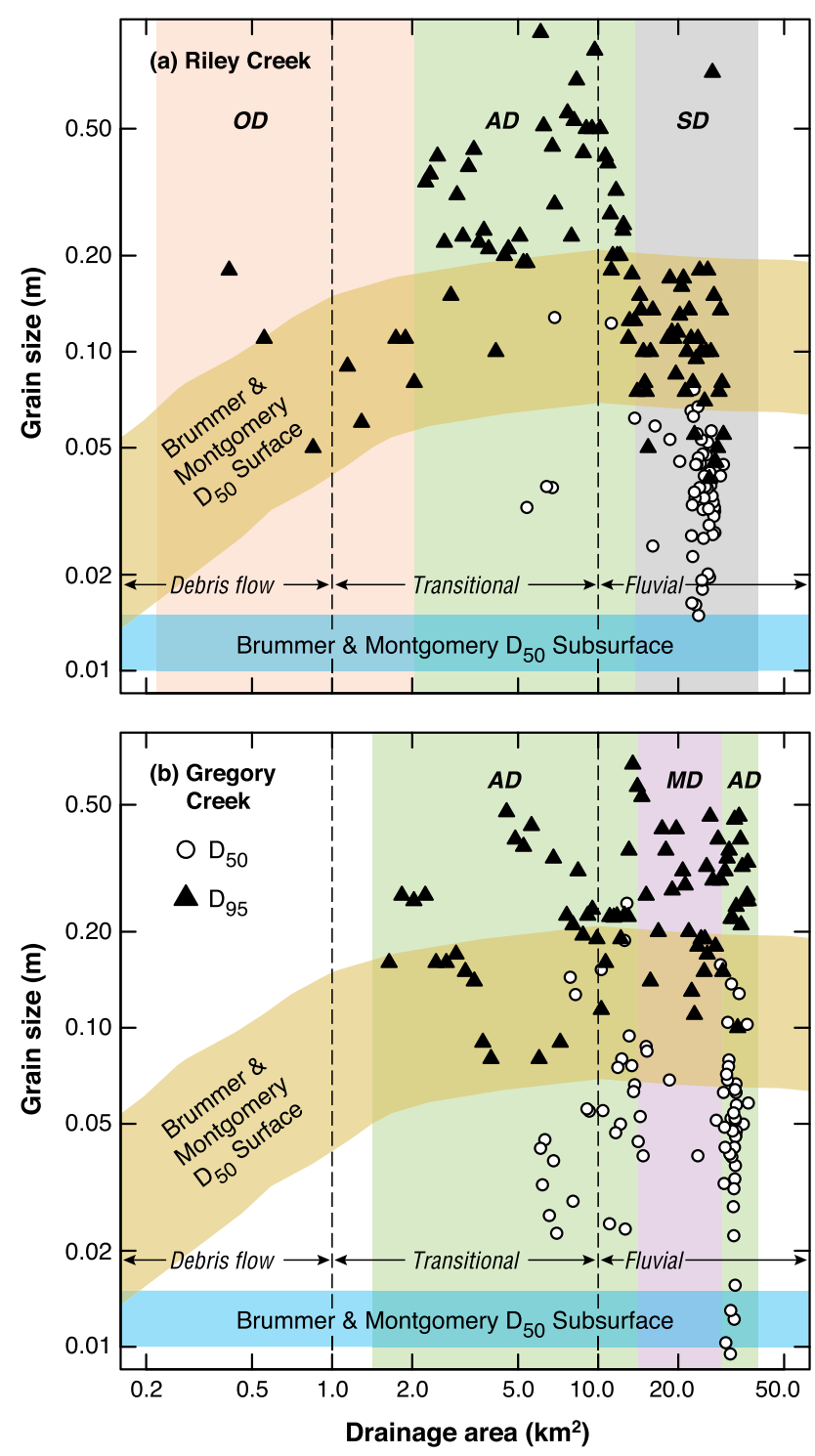

Figure 3. Plots of grain size $\left(D_{95}\right.$ and $\left.D_{50}\right)$ versus drainage basin area for Riley (a) and Gregory (b) creeks showing downstream trends in sediment texture. Schematic illustration of Brummer and Montgomery's (2003 see their Figure 10) process domains (debris flow, transition, fluvial) and downstream trends in grain size (Brummer and Montgomery $D_{50}$ surface and $D_{50}$ subsurface) are shown. Also shown is the Whiting and Bradley (1993) channel classification used to define our study reaches (see Figure 1 caption). Note that surveys and associated Whiting and Bradley Classifications extend upstream to $A_{d}$ of $0.26 \mathrm{~km}^{2}$ in Riley Creek (a), and to an $A_{d}$ of $1.63 \mathrm{~km}^{2}$ in Gregory Creek (b). [Colour figure can be viewed at wileyonlinelibrary.com]

Despite limited data available in Gregory Creek for $A_{d}<$ $2 \mathrm{~km}^{2}$, unlike Riley, no clear downstream trends in the $D_{95}$ are observed, and the data are widely scattered with large fluctuations over short distances (Figure 3(b)), though local clusters are seen at $A_{d}<5 \mathrm{~km}^{2}$. Overall, there is little correspondence with either the Brummer and Montgomery (2003) process domain break at $10 \mathrm{~km}^{2}$, or the Whiting and Bradley (1993) clas sification scheme. The $D_{50}$ of the bed surface material is equally scattered, and spans a much greater range of sizes than in Riley Creek. In reach G1 (classified AD), $D_{50}$ spans an order of magnitude over only a kilometer of channel, with some points falling into the subsurface texture zone as defined by Brummer and Montgomery (2003) (Figure 3(b)). Although the data are scattered, median grain size and the $\mathrm{D}_{95}$ percentile seems to be uncorrelated. The median size $\left(D_{50}\right)$ spans from fine grain sizes $(\sim 10 \mathrm{~mm})$ to relatively coarse grain sizes 
( 200 mm), suggesting that mass movement at streamwise position $1 \mathrm{~km}\left(\sim 3.4 \mathrm{~km}^{2}\right)$ (Figure 2(b)) might have introduced poorly sorted material to the channel.

\section{Width}

Width generally increases downstream in both channels, with exponents of the best fit lines for Riley and Gregory creeks of 0.20 and 0.34, respectively (Figure 4(a) and 4(e)). However, the data are scattered and the coefficient of determination $\left(R^{2}\right)$ for the best fit line in both creeks is low ( 0.21 for Gregory and 0.42 for Riley). The scatter in the width data vary with contributing area, with greater scatter in the lower sections of both basins $\left(A_{d}>10 \mathrm{~km}^{2}\right)$, and both channels exhibit several outlying width points (Figure 4(a) and 4(e)). Overall, the high variability in $B$ is associated with reaches that are dominated by logjams, landslides, or both (Figure 4). Channel reaches with $A_{d}>$ $10 \mathrm{~km}^{2}$ contain the greatest scatter in width and the majority of large and young jams. In Riley (Figure 4(a) (d)), this channel zone (reach $\mathrm{R} 1$ ) receives little hillslope input but has the highest frequency of jams of the study reaches. In Gregory, jam spacing is low and hillslope sediment input from recent ( $<10$ years) events is high in G1 and much of G2, while G3 received less hillslope material and has fewer jams (Fig ure $4(\mathrm{e})$ (h))

Predictions derived from the Ferrer Boix, Finnegan (gravel and boulder), and Parker width models are plotted against the respective field measured data in Figures 4 and 5 . The results reveal considerable scatter with relatively low correlation coefficients $(r)$ that range from 0.2 to 0.4 (Table SIII). The mean bias $(\mathrm{MB})$ error was calculated as the mean of the field measure ments subtracted from the mean of the model predictions. As expected, the $\mathrm{MB}$ error shows that the Finnegan Gravel width model has a tendency towards over prediction (by $10.5 \mathrm{~m}$ ), while the Finnegan Boulder width model has a tendency to wards under prediction (by $12.1 \mathrm{~m}$ ), likely reflecting the choice of channel form ratio $(\alpha)$ in the respective models. Although we use $D_{95}$ rather than $D_{50}$ for grain size, channel width is relatively insensitive to grain size with the Finnegan approach: the $1 / 6$ exponent in the Strickler formulation (Parker, 1991) along with the $3 / 8$ exponent for $n$ in the Finnegan model result in $B \propto D^{1 / 16}$. Histograms of prediction residuals show a negative skew (Figure S2) with relatively wide sections of channel (> $40 \mathrm{~m}$ ) under predicted by all models.

Relative to stratifications of $\mathrm{A}_{d}$ given by Brummer and Montgomery (2003), Finnegan (gravel and boulder) width predictions show similar patterns for Riley and Gregory creeks
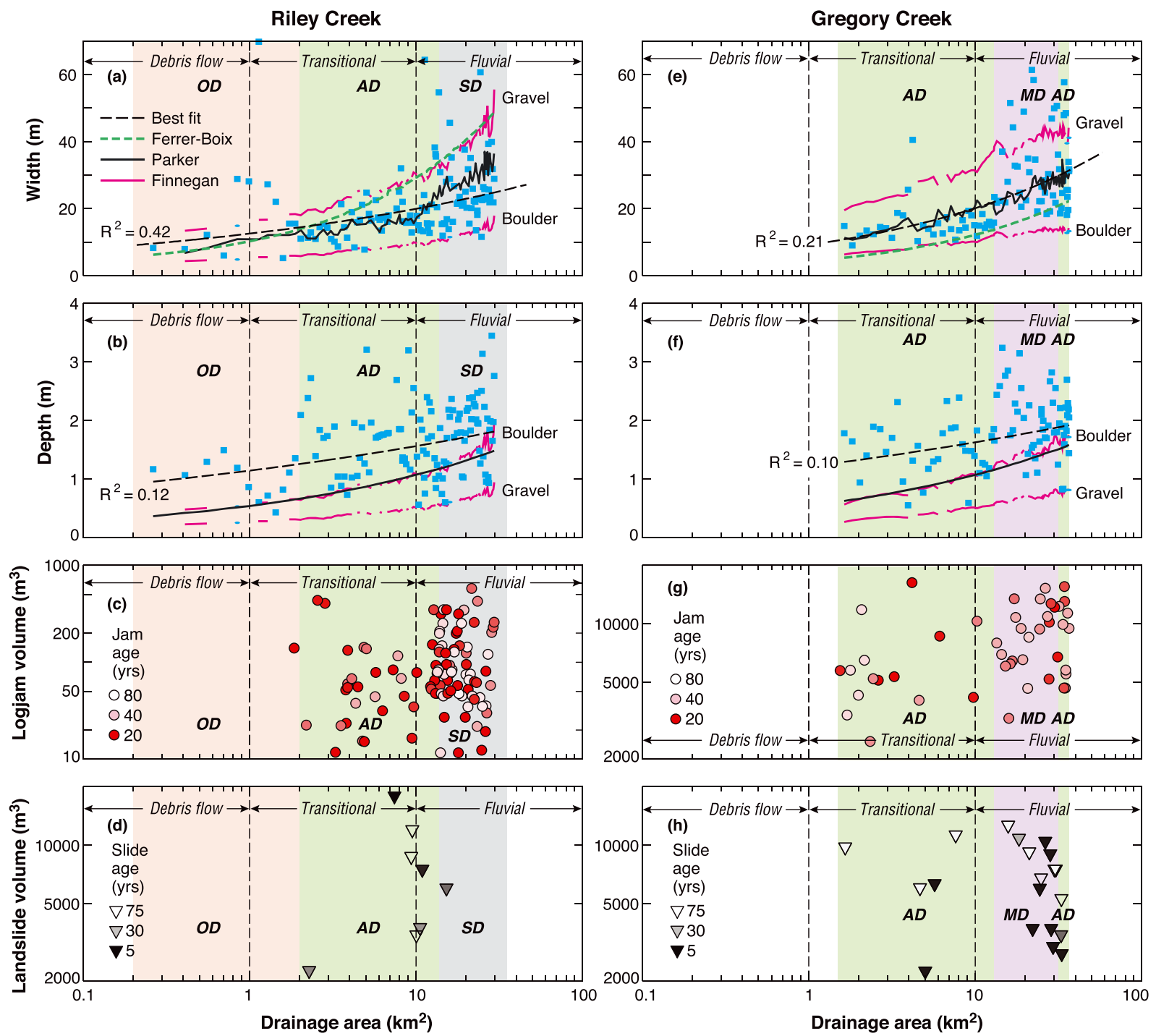

Figure 4. Plots of relations between bankfull width (B), bankfull depth (H), wood volume and age of logjams, and landslide age and volume of sed iment delivered to the channel in Riley and Gregory creeks. Best fit line, Finnegan boulder, Finnegan gravel, Parker and Ferrer Boix are shown. Also shown are Brummer and Montgomery's (2003) process domains (debris flow, transition, fluvial) and Whiting and Bradley (1993) channel classifica tion (see Figure 1 and 2 captions). [Colour figure can be viewed at wileyonlinelibrary.com] 

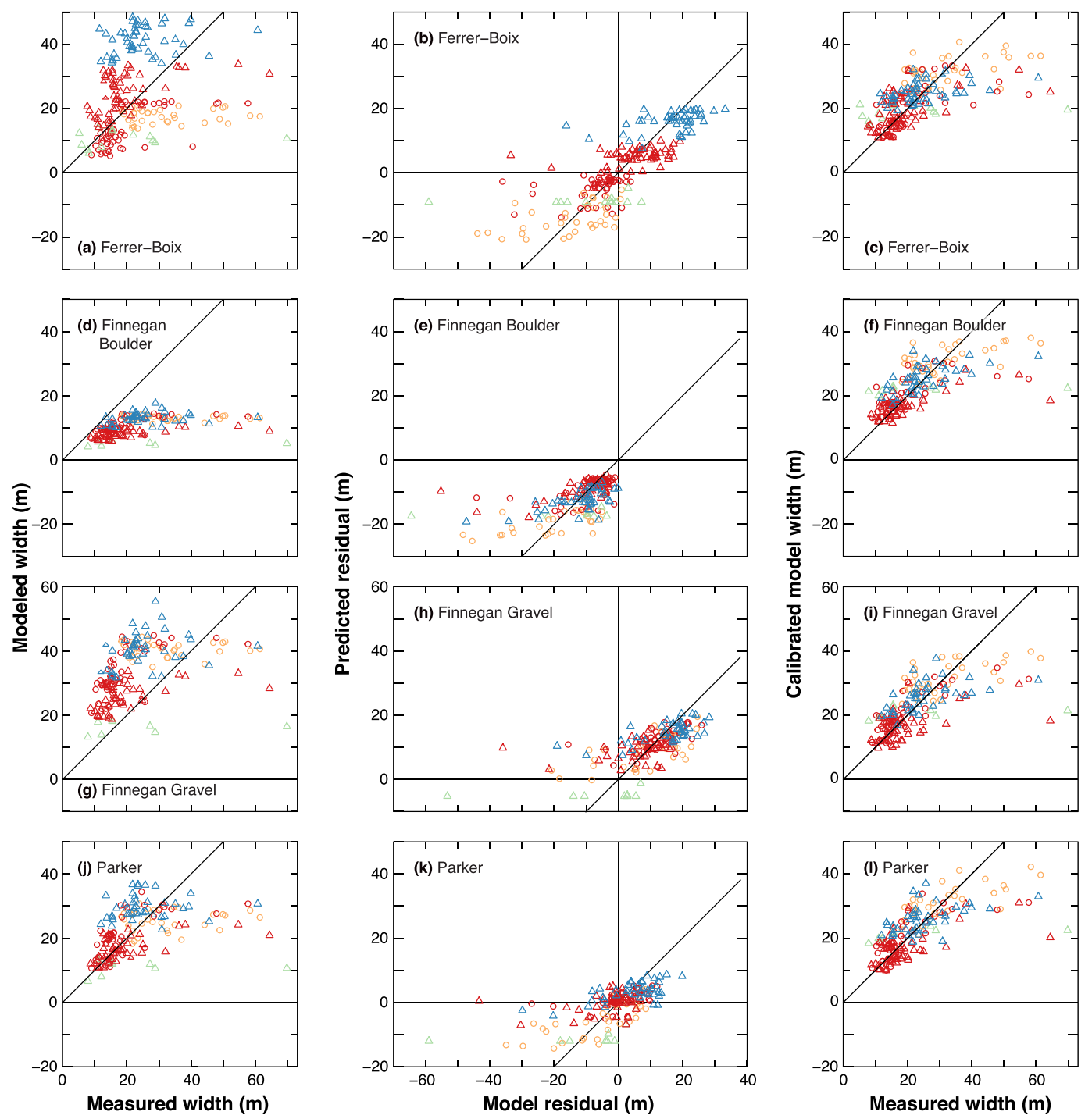

Coupling $\cdot A D \cdot M D \cdot O D \cdot S D \quad$ Basin oGregory $\triangle$ Riley

Figure 5. Scatter plots of modeled vs measured width, model residuals vs predicted residuals, and, measured and calibrated width for the Ferrer Boix (a) (c), Finnegan Boulder (d) (f) and Finnegan Gravel (g) (i) models and Parker (j) (l). Lines of 1:1 are plotted for comparison, and individual reaches are plotted with unique colours. [Colour figure can be viewed at wileyonlinelibrary.com]

(Figures 4(a), 4(e) and 5): field data are mostly contained between width calculations associated with gravel and boulder substrates. Predictions of width from the Parker model exhibit better agreement with field data compared with the Ferrer Boix and Finnegan width models (Figure 4(a), 4(e), Figure 5). Since $B \propto D^{-1 / 6}$, significantly wider channels will be predicted only when $D_{50} \ll D_{95}$ (for example, width predictions would increase by $12 \%$ if $D_{50}$ were half as coarse as $D_{95}$ ).

Lastly, width predictions for the two creeks following the methodology developed by Ferrer Boix et al. (2016) show good correspondence with width in Riley at $A_{d}<8 \mathrm{~km}^{2}$, but under predictions of width in Gregory are evident (Figure 4(a), (e) and Figure 5). This model generally aligns with the Finnegan Gravel model in Riley, and the Finnegan Boulder model in Gregory.

Results of the residual analysis using the BRT method help illuminate the prediction variability explained by hillslopechannel coupling variables that are not included in the deterministic models of width, depth or slope. A summary of modeled vs measured widths, model residuals vs predicted residuals, and calibrated vs uncalibrated widths is shown in Figure 5. The fitted BRT model coefficients and prediction statistics are given in Table SII and SIII, and a summary of included variables and their relative contribution to the final model is given in Table III. The best model fit for the width residuals occurs for the Ferrer Boix model, with a relatively high proportion of model deviance explained and a high cross validation (CV) correlation coefficient. The adjusted model deviance accounts for both the number of cases and predictors used in the BRT analysis and allows for inter model comparison. Residual deviance is the loss function being minimized by the BRT algorithm as more trees are added, and describes the correspondence between field and predicted observations.

The dominant predictor variables of Ferrer Boix width residuals include the basin itself (Riley or Gregory) (19\%), Whiting class $(19 \%)$ and volume of wood introduced to the channel from a landslide (18\%) (Table III). In contrast, the dominant predictor variable of the Finnegan width models (with boulder and gravel substrate) and the Parker width model is the volume of sediment introduced into the channel from a landslide, accounting for $43 \%, 48 \%$, and $61 \%$ of model influence, respectively (Table III). The remaining predictor variables have only a relatively minor influence (5 $10 \%$ ) on the models. Partial dependence plots (Figure S3) show the approximate effect of a predictor variable in the BRT model on model response after accounting for the effects of the other variables used in the model, and of interest is the general pattern revealed by the fitted function as it changes along the abscissa. We also include the second order interaction effects among the predictor 
Table III. Relative influence of each predictor used in the BRT analysis to model width residuals. Predictors labeled as 'omitted' were removed from the analysis if the change in predictive variance was reduced upon its removal. 'Scale' refers to the spatial extent of a variable's influence on channel conditions. The predictors are arranged in their overall importance to all models

\begin{tabular}{|c|c|c|c|c|c|c|c|c|c|}
\hline \multirow{2}{*}{ Predictor } & \multirow{2}{*}{ Scale } & \multicolumn{8}{|c|}{ Relative influence of predictor per model (\%) } \\
\hline & & \multicolumn{4}{|c|}{ Width } & \multicolumn{3}{|c|}{ Depth } & $\begin{array}{l}\text { Slope } \\
\text { Parker }\end{array}$ \\
\hline Landslide sediment volume $\left(V_{I s}\right)$ & Unit & 10.4 & 42.7 & 47.7 & 61.0 & 9.7 & 9.5 & 6.8 & 21.3 \\
\hline Landslide age $\left(T_{l}\right)$ & Unit & 15.8 & 16.2 & 4.9 & 5.7 & 13.6 & 9.0 & 16.7 & 2.5 \\
\hline Jam sediment volume $\left(V_{j s}\right)$ & Unit & 9.7 & 12.6 & 6.2 & 7.6 & 12.5 & 11.8 & 10.6 & 11.7 \\
\hline Landslide wood volume $\left(V_{l w}\right)$ & Unit & 17.8 & 7.7 & 5.3 & 3.1 & 13.6 & 14.6 & 26.6 & 3.6 \\
\hline Landslide proximity $\left(P_{l}\right)$ & Unit & 8.0 & 4.6 & 10.2 & 5.7 & 8.6 & 10.7 & 7.0 & 15.6 \\
\hline Basin area $\left(A_{d}\right)$ & Basin & Omitted & Omitted & 6.3 & 2.6 & 12.3 & 7.9 & 13.7 & 14.9 \\
\hline $\begin{array}{c}\text { Whiting and Bradley } \\
\text { classification }^{+}\end{array}$ & Reach & 18.7 & 10.3 & 6.7 & 8.1 & 3.5 & 5.7 & 2.3 & 5.8 \\
\hline Jam proximity $\left(P_{j}\right)$ & Unit & Omitted & 5.9 & 5.6 & 4.4 & 8.8 & 10.4 & 6.3 & 10.9 \\
\hline Jam age $\left(T_{j}\right)$ & Unit & Omitted & Omitted & 3.4 & Omitted & 5.4 & 6.6 & 5.3 & 6.2 \\
\hline Basin* & Basin & 19.4 & Omitted & Omitted & Omitted & Omitted & 0.0 & Omitted & Omitted \\
\hline Streambank logging & Unit & Omitted & Omitted & Omitted & Omitted & 3.7 & 4.6 & Omitted & Omitted \\
\hline
\end{tabular}

${ }^{+}$Whiting and Bradley (1993) channel classification.

*Riley or Gregory.

variables (Figure S4). For brevity, we present the first five variables in order of importance (these represent about $2 / 3$ of the relative influence of all variables in each respective model) and the two strongest interactions between variables. Considering the general pattern evident in all models, width is overestimated in Whiting class SD and AD; in proximity to large landslides (sediment volumes $>13500 \mathrm{~m}^{3}$ ) and with greatest overestimation both upstream of logjams and in Whiting class $\mathrm{SD}$ and $\mathrm{AD}$; and, in proximity to small sediment wedges stored behind logjams (sediment volumes $<3500 \mathrm{~m}^{3}$ ). Although the Finnegan model results are biased by the choice of the $\alpha$ parameter, the partial dependence plots for boulder and gravel substrates reveal a similar pattern (Figure S3).

The magnitude of the residuals generated by the four width models can be reduced by subtracting the predicted residuals derived from the BRT analysis, serving to calibrate each model with variables we selected to account for the effects of hillslope channel coupling (Table SIII). Figure 5 shows original and calibrated model $\left(B_{\mathrm{m}}\right)$ results plotted against measured values in the field $\left(B_{\mathrm{f}}\right)$. Generally, the $r$ between $B_{\mathrm{f}}$ and $B_{\mathrm{m}}$ in creased to a post calibration value of about 0.6 to 0.8 , indicating that at least some of scatter in the model output can be accounted for by our choice of variables that capture the effect of hillslope channel coupling on channel morphology. Root mean square (RMS) prediction errors for the Ferrer Boix model dropped from 14.9 to $9.3 \mathrm{~m}$ (38\%), from 16.1 to 9.0 (44\%) in the Finnegan Boulder model, from 15.4 to 9.0 (42\%) in the Finnegan Gravel model, and from 10.8 to 8.7 (19\%) for the Parker model (percentage reductions are given in parentheses). The MB error reveals that systematic error in predictions is almost eliminated. Calibration produced a small $(<0.7 \mathrm{~m})$ positive shift in the distributions, a result likely generated by the positive skew in each uncalibrated distribution (Figure S3).

\section{Depth}

Some weak positive correlation is present between $H$ and $A_{d}$ (Figure $4(\mathrm{~b})$ and $(\mathrm{f})$ ): exponents of the best fit potential curves for both Riley and Gregory creeks are 0.14 and 0.13 , respec tively, with $\mathrm{R}^{2}$ of 0.12 and 0.10 . Predictions derived from the Finnegan (Gravel and Boulder), and Parker depth models are plotted against the respective field measured data in Figure 6. The results reveal considerable scatter with a relatively low $r$ of 0.3 (Table SIII). The MB error shows that all models underpredicted channel depth with the largest under prediction occurring for the Finnegan Gravel model (Table SIII). Relative to $A_{d}$, predictions using Parker depth model and Finnegan Boulder depth models fall close and capture the lower part of the data for both basins. It should be noted that these predictions only depend on bankfull discharge (see Parker depth model, supporting information Text S1). Inspection of (a) scatter plots of modeled vs measured depth, (b) model residuals vs predicted residuals, and (c) calibrated vs uncalibrated depth (see Figure 6) indicate the similar importance of non channel geometry variables in predicting depth as for width. The most important predictor variable in the BRT analysis for the three depth models was landslide wood volume, ranging from 14 to $27 \%$ in overall influence in each BRT model. The partial dependence plots and the second order interactions between variables are given in Figures S5 and S6, respectively. Considering the general pattern evident in all models, depth is overestimated in proximity to small landslides wood volumes $\left(<1000 \mathrm{~m}^{3}\right)$ although this effect is reduced with the age of a landslide), and is also over estimated in proximity to small sediment wedges stored behind logjams (sediment volumes $<3500 \mathrm{~m}^{3}$ ). Generally, the $r$ measured between $H_{\mathrm{f}}$ and $H_{\mathrm{m}}$ increased to a post calibration value between 0.7 and 0.8 . The RMS prediction errors for the Finnegan Boulder model dropped from 0.79 to $0.35(56 \%)$, from 1.29 to $0.35(73 \%)$ in the Finnegan Gravel model, and from 0.84 to 0.44 (46\%) for the Parker model. The post calibration MB error reveals that systematic error in predictions was eliminated (Table SIII).

\section{Slope}

Plotting $S$ versus the $A_{d}$ reveals a high degree of scatter and different trends within the two basins (Figure 7). Although slope calculated from Parker Equation (6) (see Supporting information Text S1) is generally under predicted, reasonably good agreement between model and field slopes are present with a $r$ of 0.6 (Table SIII and Figure 7). Although the data are limited for areas $<2 \mathrm{~km}^{2}$, a general downstream decrease in slope was 

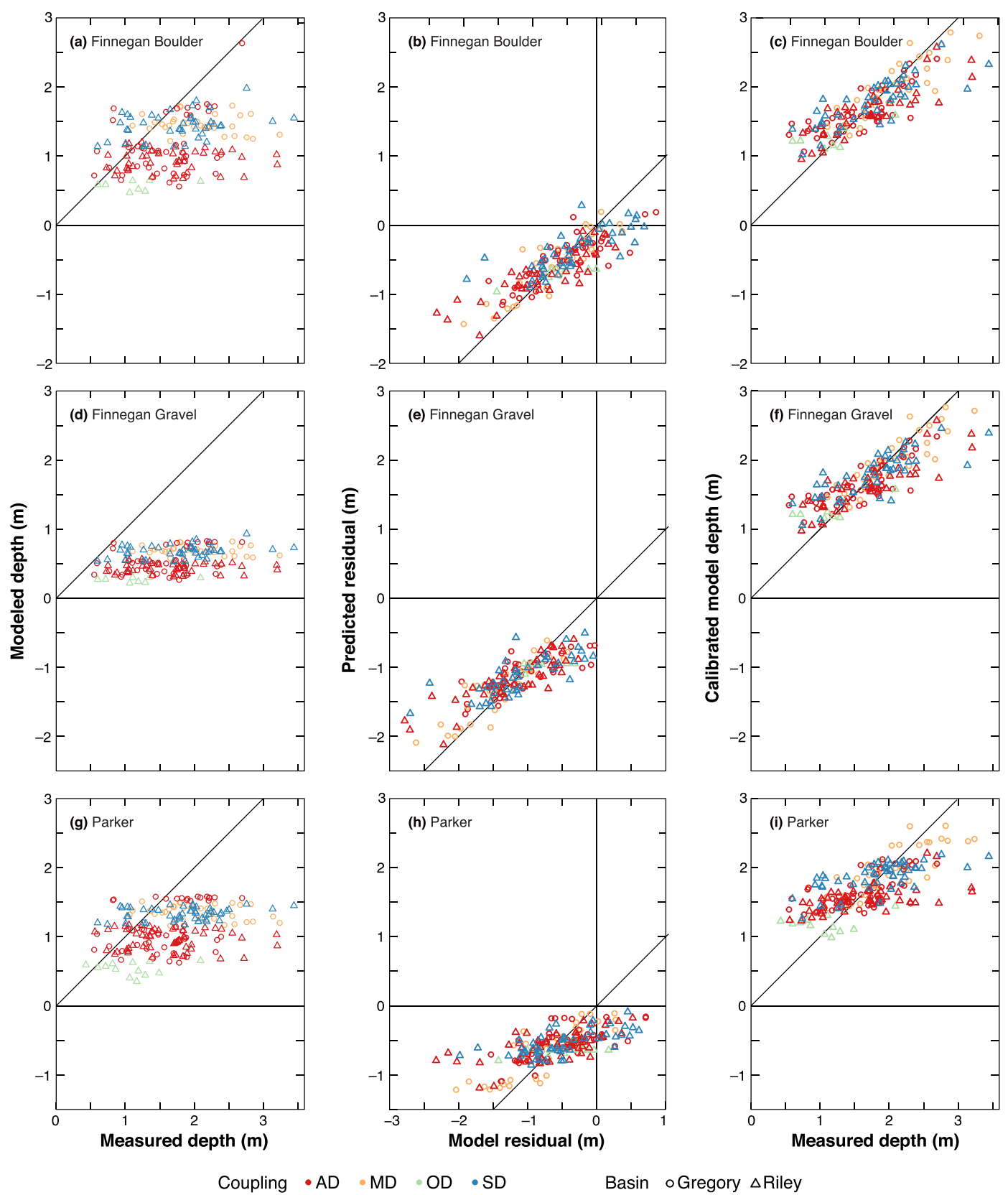

Figure 6. Scatter plots of modeled vs measured depth, predicted vs model depth residuals, and measured vs calibrated depth for the Parker (a) (c), Finnegan Gravel (d) (f) and Finnegan Boulder models (g) (i). Lines of 1:1 are plotted for comparison. [Colour figure can be viewed at wileyonlinelibrary.com]

obtained for Gregory Creek, indicating a concave upward longitudinal profile (Figure $7(\mathrm{~b})$ ). However, a more complex relation was obtained for Riley Creek (Figure 7(a)): slope initially decreases $\left(A_{d}<1 \mathrm{~km}^{2}\right)$, followed by an increase between 1 and $10 \mathrm{~km}^{2} A_{d}$, and a general decrease for $A_{d}>10 \mathrm{~km}^{2}$ (Figure $7(\mathrm{a})$ ). For Riley Creek, the steep channel segment $\left(1 \mathrm{~km}^{2}<A_{d}<10 \mathrm{~km}^{2}\right)$ coincides with the increase in the $D_{95}$ of the bed material (Figure 3(a)). No significant correlation exists between $\mathrm{D}_{95}$ and slope for Gregory Creek (Figure $7(\mathrm{~d})$ ). While the expression for bed slope developed by Parker captures the main features in Riley Creek (Figure 7(c)), the expression performed relatively poorly for Gregory Creek (Figure $7(d)$ ). Given the sensitivity of slope to local conditions, slope averaged over 15 bankfull channel widths is also plotted in Figures 7 (c) and (d). Overall, both the raw and averaged slope data yielded similarly scattered patterns.

Predictions derived from the Parker slope model are plotted against the field measured data in Figure 8, the partial dependence plots in Figure S7, and the second order interactions between predictors in Figure S8. The most important BRT predictor variable was landslide sediment volume (21\%), followed by proximity to a landslide and basin area (16 and $15 \%$, respectively) (Table III). The patterns revealed by the partial dependence plots (Figure S5) are generally more complex than those shown for the width and depth models. The model over estimated channel slope in proximity to small landslide sediment volumes and small sediment wedges $(<13500$ and $<4000 \mathrm{~m}^{3}$ of sediment, respectively), but this over estimation generally declined with increasing volumes of sediment. The model under estimated slope upstream of a landslide and over estimated slope downstream of a landslide, and the second order interactions show that these residuals all shift in the positive direction with decreasing landslide sediment volumes. The fitted function for basin area shows a complex relation, with steps between about 3 and $10 \mathrm{~km}^{2}, 10$ and $13 \mathrm{~km}^{2}$, and then 13 to $30 \mathrm{~km}^{2}$. Again, these residuals all shift in the positive direction with decreasing landslide sediment volumes. Calibration increased the $r$ to a value near 0.8, while the RMS 

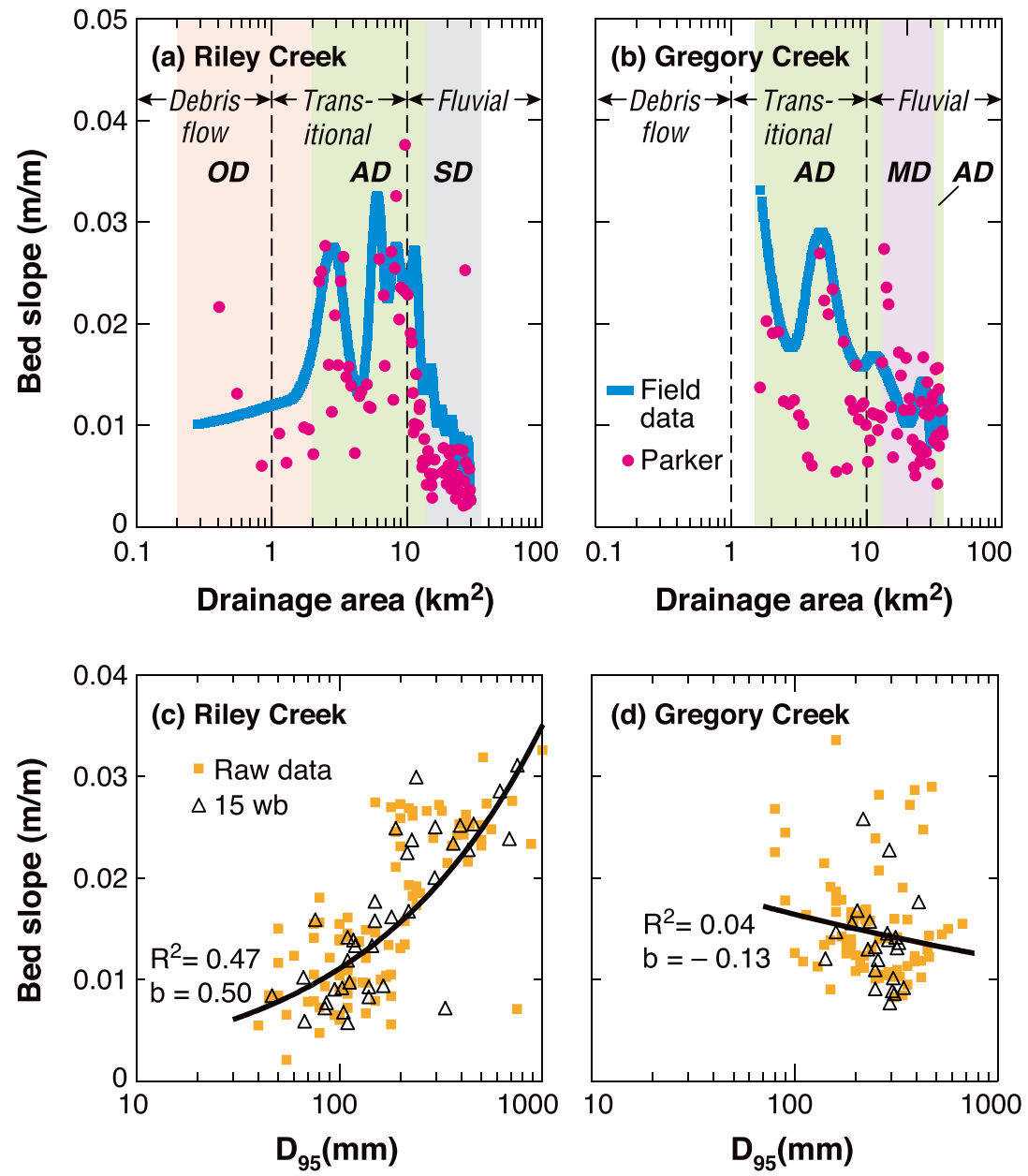

Figure 7. Plots showing the relation between channel slope (S), drainage basin area and $\mathrm{D}_{95}$ of Riley and Gregory creeks. The field data in panels (a) and (b) were smoothed using splines. Parker slope model is shown for comparison (panels (a) and (b)) and best fit line (panels (c) and (d)). b in panels (c) and (d) indicates the exponent of the best fit potential line (for the raw data). [Colour figure can be viewed at wileyonlinelibrary.com]
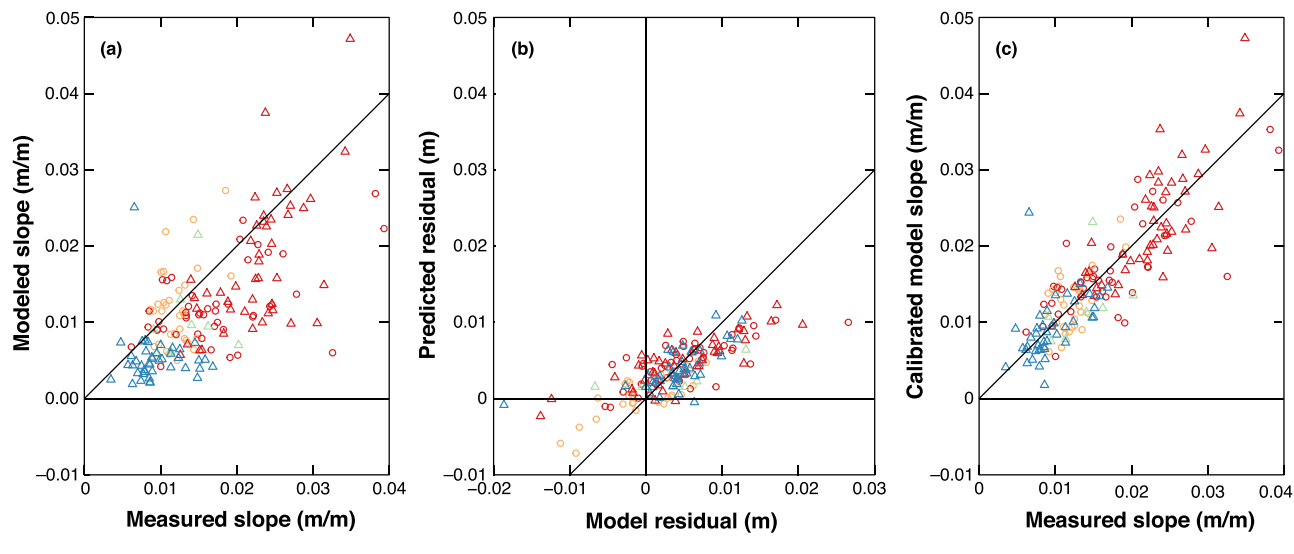

Coupling $\cdot A D \cdot M D \cdot O D \cdot S D \quad$ Basin oGregory $\triangle$ Riley

Figure 8. Scatter plots of modeled and measured slope (a), predicted and model slope residuals (b), and measured and calibrated slope (c) for the Parker model. Lines of 1:1 are plotted for comparison. [Colour figure can be viewed at wileyonlinelibrary.com]

prediction error dropped from 0.007 to $0.004(43 \%)$, and the MB error was eliminated (Table SIII).

\section{Discussion}

Process domains and landscape history

A comparison of our field data with the process based Brummer and Montgomery (2003) and Whiting and Bradley
(1993) classifications suggests that landscape setting, and in particular glacially inherited topography, must be considered in the evaluation of basin process domains.

Overall, field data from both channels matched the Whiting and Bradley (1993) classification reasonably well: reaches classified as 'coupled' (AD and MD) are associated with a high degree of sediment and wood delivery from hillslopes (Figure 3), while decoupled (OD and SD) reaches receive little material. Interestingly, divide breaching in both study streams results in gentle adjoining valley sides and virtually no colluvial 
sediment inputs to the channel main stems in G2, R3, and the uppermost part of R2. This observation suggests that one should take into account the proportion of adjoining valley walls steep enough to host mass wasting activity, a condition that Whiting and Bradley's scheme does not consider. In addition, the distinction between $\mathrm{AD}$ and MD classes appears difficult to capture over the century scale: for example, the MD classed reach in Gregory received more hillslope input per unit length (Table SII), than any of the three AD classed reaches. Where hillslope sediment input is infrequent and episodic, longer timescales may be needed to make distinctions between reaches with only slightly different degrees of coupling.

The better agreement between our data and the Whiting and Bradley (1993) classification, versus the Brummer and Montgomery (2003) classification can be attributed to the significance of landscape history and localized hillslope inputs in both study channels. Traditional landscape process domains usually involve upland coupling to hillslopes, which decreases as one travels downstream (Church, 2002; Brummer and Montgomery, 2003). However, glaciated regions, such as the Riley and Gregory creek basins, may not show clear down stream trends (Brardinoni and Hassan, 2006) and a channel may be coupled or decoupled to hillslopes almost anywhere along its length. These localized conditions, apparent in our study channels, result in difficulties with fitting the data to more general catchment scale models, such as the Brummer and Montgomery (2003) domains, and illustrate the strengths of classification approaches that capture localized conditions in glaciated catchments.

\section{Particle size}

Within the Brummer and Montgomery (2003) process domains, the conceptual model of downstream progression in particle size shows good agreement with data from Riley Creek, but not that of Gregory Creek (Figure 3). Though our data are composed mainly of $D_{95}$ particle size, the trend of increasing $D_{95}$ in Riley closely matches the Brummer and Montgomery (2003) model for median grain size. In the fluvial domains of Riley Creek, a sharp decrease in $D_{95}$ is observed whereas the Brummer and Montgomery (2003) model suggested a slight decrease in the median size of the bed surface material. The Brummer and Montgomery (2003) model attributes finer median particle sizes to upland reaches dominated by debris flows, followed by downstream coarsening into transitional reaches, and subsequent fining into fluvially dominated environments. In Riley, however, the highest degree of coupling does not occur upstream, but rather towards the middle of the basin, in the region described by Brummer and Montgomery (2003) as 'transitional'. Clearly, glaciation in this case has moved the transitional part toward the middle part of the basin. The finer $D_{95}$ in the headwater reach (R3) and coarser in the mid reach (R2) do appear to correspond to hillslope channel coupling, but not in the way described by the Brummer and Montgomery (2003) model, as the uppermost reach in Riley is largely free of slope failures and is set into a relatively wide valley bottom. Sediment to this reach (R3) is most likely delivered from steeper tributaries which do receive inputs of hillslope material, or from lateral erosion of relict deposits of glacial sediment (Hassan et al., 2016).

The high degree of downstream coarsening and subsequent fining in Riley Creek (Figure 3(a)) appears to be largely a function of coarse particle input from hillslopes, although there is a clear relation between $D_{95}$ and channel gradient (Figure $7(\mathrm{c})$ ). Though our data are not of sufficient resolution to link coarse particles to individual slides, the observed patterns in Riley correspond well to the coarse lag deposits described by Brummer and Montgomery (2006) for debris flow affected channels in California. In Gregory Creek, $D_{95}$ shows no clear downstream trend, and generally spans a similar range of values to reach R2 in Riley, suggesting that input of hillslope material is adding coarse particles along much of the channel length. While the $D_{50}$ data from Rice (1994) are not of sufficient spatial resolution to clearly capture downstream trends, particles are generally coarser in the coupled AD reach of Riley, than the decoupled SD reach, and in general fall below the sizes found by Brummer and Montgomery (2003). In Gregory Creek, $D_{50}$ shows much more variability over short distances, again potentially a product of the spatially distributed slope failures and logjams along Gregory Creek.

The scatter in the $D_{95}$ and $D_{50}$ for both creeks could be due to inputs from landslides entering the channels at drainage area larger than $2 \mathrm{~km}^{2}$ (within the transitional and fluvial zones) and because of the presence of logjams. At the unit scale, Rice (1994, 1995) studied the influence of logjam on sediment sorting along both creeks. Depending on age and functionality of the logjams, he reported differences in the $D_{50}$ of the bed material upstream and downstream of the jams. The channel bed sediment upstream of jams is usually finer and composed of trapped sediment, while the lower part is coarser with little or no sediment storage. However, Rice $(1994,1995)$ noted that while this effect was clearly observed for several well devel oped jams in both Riley and Gregory, the degree of the effect is a function of both jam age, integrity, and the span of the structure relative to the channel width. In our study, for several jams we noted differences in sediment texture up to distances of several hundred meters, indicating that the spatial influence in texture could be potentially larger than previously expected.

\section{Channel geometry}

Overall, the models of Ferrer Boix et al. (2016), Finnegan et al. (2005), and Parker et al. (2007) captured the general trends in channel width, depth and slope but did not account for variability imposed by local conditions stemming from features such as landslide deposits and logjams. The generally better performance of the Parker width model relative to the Ferrer Boix and the Finnegan width models likely reflects the fact that the Parker model explicitly accounts for variation in grain size, whereas Ferrer Boix and Finnegan implicitly account for grain size variation through the critical stress and Manning's $n$ variables, respectively. This is an important distinction because the spatial organization of hillslope channel coupling observed in Gregory and Riley creeks exerts a strong influence on the as sociated spatial organization of bed surface grain sizes.

According to Ferrer Boix et al. (2016), channel width in both creeks is best described when using typical values of $\tau_{b}{ }^{*} / \tau_{c}{ }^{*}$ for gravel bed rivers: 2 and 1.25 for Riley and Gregory creeks, respectively (Figure S9 and S10). However, surface texture in Figure 3 renders much higher values of the ratio $\tau_{b}{ }^{*} / \tau_{c}{ }^{*}$ which in turn lead, according to Ferrer Boix et al. (2016), to narrower channels. If this method was taken to accurately describe channel width of gravel bed rivers, these results would suggest that Riley and Gregory creeks have coarser bed material than their channel width indicates. This is in agreement with results from the Finnegan (Figure 5) and Parker models: higher values of channel width in the latter would be obtained in cases where $\mathrm{D}_{50} \ll \mathrm{D}_{95}$. To summarize, all the model predictions suggest that both Riley and Gregory creeks should have coarser bed surface textures than predicted given the observed channel widths, or equivalently, observed channel width in both creeks 
is wider than anticipated. This channel widening might be at tributed to inputs of coarse sediment and LW entering the river bed from mass wasting events and subsequent channel adjust ment, thus providing evidence for the role played by these events in casting morphologies of mountain streams.

The Finnegan and Parker models do not perform as well for predictions of depth (Figures 4 and 6). All three models predict near the bottom of the data, with the Finnegan Boulder and Parker models giving very similar predictions. These underpredictions might be attributed to both the presence of logjams in the channel and the coarse surface texture observed. On one hand, logjams as obstacles to flow create a backwater zone in their upstream side that contributes to reduce mean flow velocity and to raise local water surface elevations. As described earlier (Rice, 1994), these conditions enhance sediment accumulation, often displayed as a reduction in bed slope. At the same time, sediment trapping on the upstream side of logjams leads to channel degradation on their downstream side, and therefore greater depths. Predictions of channel bed slope from the Parker model (Figure 7 and 8) are generally greater than observed, but in a few locations slope is under predicted. In Riley Creek, the general pattern of slope is followed quite closely, with fairly accurate predictions in regions of higher gradient (e.g. reach R2), but shifted above our data elsewhere. While slope data generally falls around the Parker model predictions in Gregory, predictions here do not capture the high variability in slope over short distances in reaches G3 and G2. Predictions in G1 better capture some of the variability in the data.

Further insight is gained by considering the residuals generated by the model predictions of width, depth and slope. At the unit scale, the BRT analysis shows that the width and depth models generally over predict in proximity to recent landslides, and that this effect on the width and depth models persists for about 7085 years and 4590 years, respectively. These time scales are roughly equivalent to the residence time of LW and the age of the oldest logjams in both channels (Hogan et al., 1998; Hassan et al., 2016). These over predictions were also observed in proximity to relatively small landslides (i.e. $<13$ $500 \mathrm{~m}^{3}$ and $<1000$ to $1700 \mathrm{~m}^{3}$ of sediment and wood delivered to a channel, respectively) and for small volumes of sediment (i.e. $<3600$ to $4400 \mathrm{~m}^{3}$ ) stored behind logjams. Both slope and width were over predicted upstream of a landslide, and then under predicted on the downstream side. Although not all models strictly conformed to this pattern, we suspect that in general, the relatively poor performance of the models before calibration results from changes in local roughness induced by relatively small inputs of coarse particles and LW from adjacent hillslopes to the channel that result in changes in local channel geometry as logjams develop and evolve over time. These inputs add a stochastic element to the geometry as they fall below the spatial resolution for which the models were designed, whereas larger inputs can be better accounted for in the model formulation. At the reach scale, the Whiting and Bradley classification integrates these unit scale deviances in model prediction and their interaction along the channel. All four width models over predicted in Whiting and Bradley clas sifications SD and AD and under predicted in classes OD and MD. Only the Ferrer Boix width model was influenced at the basin scale, with channel widths in Riley and Gregory creeks over and under predicted, respectively.

Overall, calibration using the BRT residual modeling im proved width predictions by $16 \%, 40 \%, 42 \%$, and $43 \%$ for the Parker, Ferrer Boix, Finnegan Boulder and Finnegan Gravel models, respectively. This finding is noteworthy as it implies the significance of hillslope channel coupling and wood variables in affecting channel form (Figure 4, 5, and 7). The width residuals are generally well modeled by the BRT analysis up to channel widths of about $40 \mathrm{~m}$. Beyond this limit, overwidening of the channel in relation to large, laterally expansive jams are not well predicted by our choice of BRT variables (Figure 5).

Several predictor variables were omitted from the various BRT models (Table III). Streambank logging was omitted from most models and, when included, only accounted for 4 to $6 \%$ of the overall model influence. The basin itself (Riley or Gregory) was another poor predictor in all but the Ferrer Boix width model where it was the most influential predictor of model residuals. $A_{d}$ was included in the analysis to account for scale changes in residuals measured in the headwaters to those measured near the outlet of the basin. However, $A_{d}$ was another relatively poor predictor, representing only 3 to $15 \%$ of model variance and was omitted in two models (Table III). Although the omission of a predictor variable may imply unimportance for prediction of width, depth or slope, it may also instead indicate that the various deterministic models sufficiently account for the effect of the variable in the first place, so that the residuals produced by the model relate only to other predictor variables. Generally, the predictor variables that affected the channel on the unit scale had the largest influence on a given BRT model.

\section{Implications}

In this study, we have demonstrated the relative importance of (a) basin morphometry and history on hillslope channel coupling, (b) hillslope channel coupling on landslide mediated delivery of wood and sediment inputs, and (c) the interactions of these variables with channel morphology characteristics of two forested mountain streams. Much of the variability of channel dimensions at the unit, reach and basin scales (assessed from analysis of model residuals) is associated with input of sediment and wood from hillslopes and the formation of logjams, variables that depend on the local degree of hillslope channel coupling. Models of channel width, depth, and slope, such as those we have applied, do not consider these additional variables in their predictions and therefore are likely to produce poor results in such environments.

In a downstream coupling system, the connection between channels and adjacent hillslopes declines in the downstream direction and with it the quantity of solid material input directly originating from hillslopes. As a result, direct inputs of wood and sediment from adjacent hillslopes are limited to headwater streams. Further downstream, solid material is intercepted by the presence of a valley bottom that stores material until the channel migrates laterally across the floodplain and eventually re mobilizes stored wood and sediment through bank erosion. Although LW and logjams may be present in these channels, the morphology is more likely to depend on the flow conditions (discharge), local sediment supply, and gradient. The general configuration and morphometry of basins within a downstream coupling system is shown in Figure 9(a). The valley bottom width and depth of alluvium in this model grow in proportion to increasing basin area, and the channel develops an upward concave longitudinal profile given a progressive increase in discharge and fining of bed material sediment once the channel reaches the valley bottom. Patterns of downstream coarsening in the coupled reaches and downstream fining in the decoupled reaches follow the process domains of the Brummer and Montgomery (2003) model. The transitional reaches between coupled and decoupled portions of the model may perturb these patterns where the valley walls or landslide deposits impinge locally upon the channel banks. 


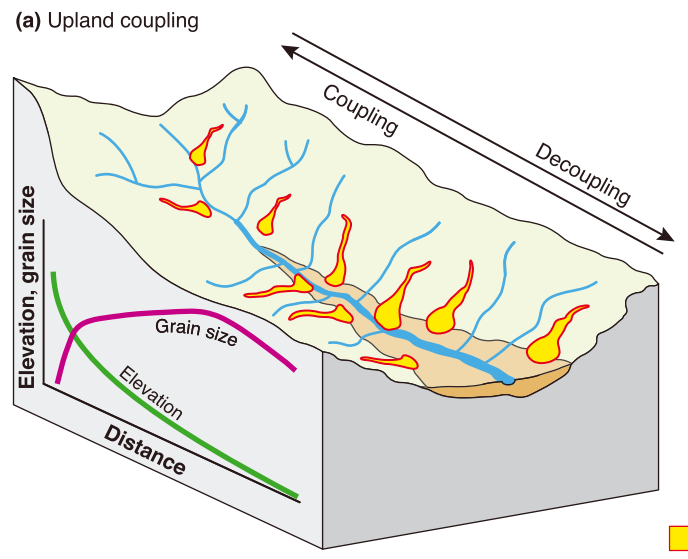

(b) Variable downstream coupling: stepped

long profile

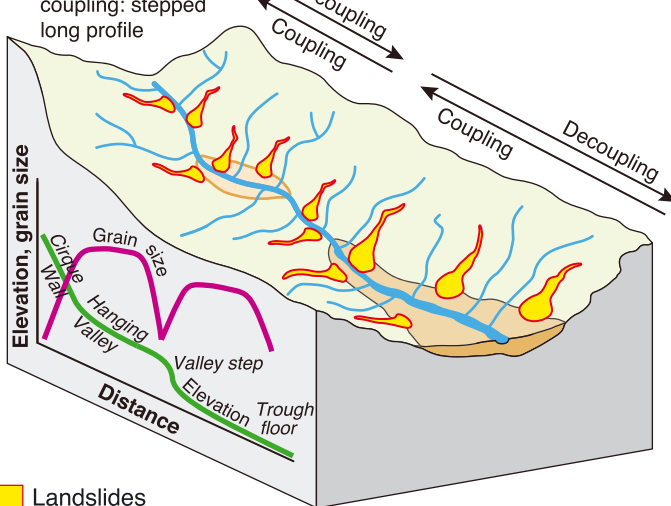

(c) Variable downstream coupling:

Floodplain lateral divide breaching

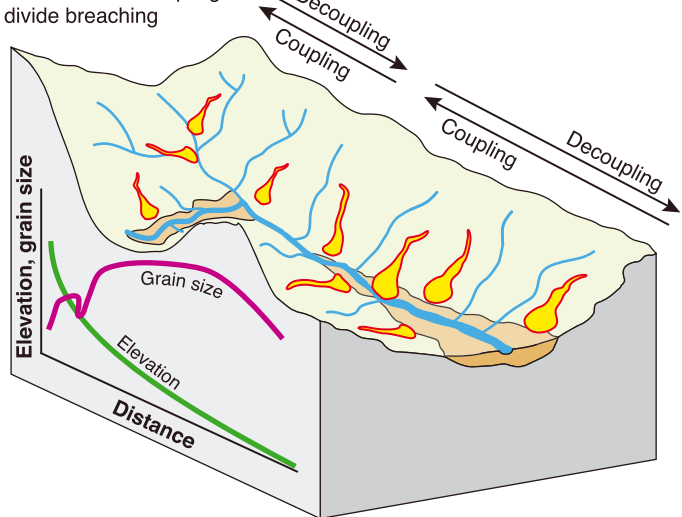

Figure 9. Conceptual model of (a) upland hillslope channel coupling, (b) variable downstream hillslope channel coupling, and (c) variable down stream hillslope channel coupling by lateral divide breaching. [Colour figure can be viewed at wileyonlinelibrary.com]

In contrast, we conceptualize a system of variable downstream coupling where basin morphometry is controlled by past glaciation (Figures $9(\mathrm{~b})$ and (c)). The spatial distribution of coupled and decoupled reaches in such a model reflects the spatial arrangement of relict erosional glacial macro forms as carved by relict ice flows, and their scale relative to prevailing channel dimensions as controlled by discharge. Macroforms such as cirques, hanging valleys, valley steps and troughs typically give rise to stepped longitudinal profiles that alternate coupled (V notched valley cross section) and uncoupled reaches ( $U$ shaped valley cross sections) (Brardinoni and Hassan, 2006) (Figure 9(b)). In glaciated settings dominated by inter basin ice flow transfluence, widespread drainage divide breaching has produced a highly dissected landscape characterized by nearly concave up long profiles, but extremely variable downstream patterns of hillslope channel coupling (Figure 9(c)). The Riley and Gregory basins are examples of this latter scenario. Channel geometry and bed texture in our model depart from expected trends and channels may be coupled anywhere along their length, and have geometry and particle size modified by hillslope input of sediment, wood, and resulting wood structures. The process domains of the Brummer and Montgomery (2003) model are interrupted and repeated and patterns of downstream coarsening and subsequent fining of surface sediments are masked by this lack of spatial organization.

Our findings, in particular the analysis of model residuals, provide evidence for a link between the configuration in Figure 9(b) and channel width, depth, slope, and grain size, lending support to our hypothesis that landscape form has substantial bearing on the characteristics of finer scale variables in the channels. While incorporating our results into prediction is challenging without a better understanding of the causal mechanisms between hillslope coupling and channel form, the contrast between the styles of catchments shown in Figure 9 provides a useful means with which to assess the applicability and likely prediction bias of traditional models of channel form in a given catchment.

\section{Conclusion}

We present and explore how downstream patterns in hydraulic geometry and bed surface texture vary for two mountainous watersheds which were ice covered during the Fraser glaciation. Our results demonstrate that the degree of hillslope channel coupling, as imposed by past glacial activity, governs downstream variations to channel size and bed surface roughness, which can change rapidly with drainage area depending upon the coupling state. This work expands upon that of Brummer and Montgomery (2003) who showed, for example, that four basins of western Washington were described by a relatively clear pattern of downstream coarsening and subsequent fining as headwater channel networks transition from debris flow dominated to fluvially dominated watershed processes. In the two Haida Gwaii basins, we were unable to identify downstream trends consistently fitting the Brummer and Montgomery (2003) model. Our data proved to mimic more closely the channel coupling states described by the Whiting and Bradley (1993) classification approach. To examine and help explain observed downstream patterns of channel character in relation to the two classification systems, we used four different theoretical models of downstream channel width variation, three of depth, and one of slope. Model residuals were then analyzed with the machine learning method of Boosted Regression Trees machine learning in order to explore possible 
explanations for observed downstream variability in width, depth and slope.

Predictions of width, depth and slope were compared with field data from the two basins, revealing notable differences in model performance in relation to different channel configurations, coupling states, and glacial macroforms. The analysis of residuals generated by the models of channel width, depth, and slope also illustrate the importance of variables not considered by the respective models, including how the glacially inherited topography of the Riley and Gregory basins conditions post glacial channel development. Results from this approach suggest that variables related to landslides and logjams (volume, proximity, and age) influence much of the variance in the model predictions, and also that explicit consideration of the degree of coupling (Whiting and Bradley (1993) classification) is needed. Finally, our results reinforce the importance of landscape, and emphasize the relative importance of glacial history, highlighting that the glacial legacy can disrupt downstream gradients in channel geometry, sediment texture and other key variables, which typify downstream concave river profiles. These results work towards improving a generalized understanding of how landscape history influences landscape organization, which in turn drives local channel form, structure, and process in previously glaciated regions.

Acknowledgements We thank Sid Tsang, Alan Paige, Tony Cheong, Steve Rice, and Dave Ramsey for their assistance in the field; Jim Schwab and his colleagues for compiling and sharing the landslide in ventory; and, Steve Rice for sharing his bed material texture data. This research was funded in part by the Fish/Forestry Interaction Program II sponsored by the British Columbia Ministry of Forests and Lands. Eric Leinberger prepared the figures and Sara Rathburn read an early draft of the paper. We thank the journal editors and two anonymous reviewers for suggestions that significantly improved the presentation.

\section{References}

Alley NF, Thomson B. 1978. Aspects of environmental geology, parts of Graham Island, Queen Charlotte Islands. British Columbia Ministry of Environment, Resource Analysis Branch Bulletin: No. 2.

Benda LE, Dunne T. 1997a. Stochastic forcing of sediment routing and storage in channel networks. Water Resources Research 33: 28652880

Benda LE, Dunne T. 1997b. Stochastic forcing of sediment supply to channel networks from landsliding and debris flow. Water Resources Research 33: 28492863.

Benda LE, Sias J. 2003. A quantitative framework for evaluating the wood budget. Forest Ecology Management 172: 16 .

Bracken LJ, Turnbull L, Wainwright J, Bogaart P. 2015. Sediment connectivity: a framework for understanding sediment transfer at multiple scales. Earth Surface Processes and Landforms 40:177 188.

Brardinoni F, Hassan MA. 2006. Glacial erosion, evolution of river long profiles, and the organization of process domains in mountain drainage basins of coastal British Columbia. Journal of Geophysical Research 111 F01013, https://doi.org/10.1029/2005JF000358.

Brardinoni F, Hassan MA. 2007. Glacially induced channel reach morphology in mountain streams. Journal of Geophysical Research 112 F03013, https://doi.org/10.1029/2006JF000741.

Brardinoni F, Hassan MA, Slaymaker O. 2003. Complex mass wasting response of drainage basins to forest management in coastal British Columbia. Geomorphology 49: 109124.

Brocklehurst SH, Whipple KX. 2004. Hypsometry of glaciated landscapes. Earth Surface Processes and Landforms 29: 907926.

Brummer CJ, Montgomery DR. 2003. Downstream coarsening in head water channels. Water Resources Research 39: 1294. https://doi.org/ 10.1029/2003WR001981.

Brummer CJ, Montgomery DR. 2006. Influence of coarse lag formation on the mechanics of sediment pulse dispersion in a mountain stream, Squire Creek, North Cascades, Washington, United States. Water
Resources Research 42: W07412, https://doi.org/10.1029/2005 WR004776

Brummer CJ, Abbe TB, Sampson JR, Montgomery DR. 2006. Influence of vertical channel change associated with wood accumulations on delineating channel migration zones, Washington, USA. Geomor phology 80: 295309.

Church M. 2002. Geomorphic thresholds in riverine landscapes. Freshwater Biology 47: 541557.

Elith J, Leathwick JR, Hastie T. 2008. A working guide to boosted regression trees. Journal of Animal Ecology 77: 802881.

Ferguson RI. 1986. Hydraulics and hydraulic geometry. Progress in Physical Geography 10: 131.

Ferrer Boix C, Chartrand SM, Hassan MA, Martin Vide JP, Parker G. 2016. On how spatial variations of channel width influence river profile curvature. Geophysical Research Letters 43: 63136323.

Finnegan NJ, Roe G, Montgomery DR, Hallet B. 2005. Controls on the channel width of river: implications for modeling fluvial incision of bedrock. Geology 33: 229232.

Gimbarzevsky P. 1988. Mass Wasting on the Queen Charlotte Islands: A Regional Inventory, Land Management Report No. 29. British Columbia Ministry of Forests: Victoria, British Columbia; 107.

Gomi T, Sidle RC, Richardson JS. 2002. Understanding processes and downstream linkages of headwater systems: headwaters differ from downstream reaches by their close coupling to hillslope processes, more temporal and spatial variation, and their need for different means of protection from land use. BioScience 52: 905916.

Grant GE, Swanson FJ. 1995. Morphology and processes of valley in mountain streams, Western Cascades, Oregon. In Natural and Anthro pogenic Influences in Fluvial Geomorphology, Vol. 89, Geophysical Monograph. American Geophysical Union: Washington, DC; 83101.

Hassan MA, Bird S, Reid D, Hogan D. 2016. Simulated wood budgets in two mountain streams. Geomorphology 259: 119133.

Hastie T, Tibshirani R, Friedman J. 2009. The Elements of Statistical Learning: Data Mining, Inference, and Prediction, 2nd edn. Springer Science and Business Media.

Hijmans RJ, Phillips S, Leathwick J, Elith J. 2017. Dismo: Species Distri bution Modeling. R package version 1.1 4, URL: https://CRAN.R pro ject.org/package $=$ dismo.

Hogan DL, Bird SA, Hassan MA. 1998. Spatial and temporal evolution of small coastal gravel bed streams: the influence of forest manage ment on channel morphology and fish habitats. In Gravel Bed Rivers in the Environment. Water Resources Publications: Colorado; 365392.

James G, Witten D, Hastie T, Tibshirani R. 2013. An Introduction to Statistical Learning: With Applications in R. Springer Science and Business Media.

Leopold LB, Maddock T, Jr. 1953. The hydraulic geometry of stream channels and some physiographic implications. US Geological Survey Professional Papers 252: 57

Livers B, Wohl E. 2015. An evaluation of stream characteristics in glacial versus fluvial process domains in the Colorado Front Range. Geomorphology 231: 7282.

Martin Y, Rood K, Schwab J, Church M. 2002. Sediment transfer by shallow landsliding in the Queen Charlotte Islands, British Columbia. Canadian Journal of Earth Sciences 39: 189205.

May CL, Gresswell RE. 2003. Large wood recruitment and redistribu tion in headwater streams in the southern Oregon coast range, USA. Canadian Journal of Forest Research 33: 13521362.

Montgomery DR. 2002. Valley formation by fluvial and glacial erosion. Geology 30: 10471050.

Montgomery DR, Buffington JM. 1997. Channel reach morphology in mountain drainage basins. Geological Society of America Bulletin 109: 596611.

Montgomery DR, Foufoula Georgiou E. 1993. Channel network source representation using digital elevation models. Water Resources Research 29: 39253934.

Nakamura F, Swanson FJ. 1993. Effects of coarse woody debris on mor phology and sediment storage of a mountain stream system in west ern Washington. Earth Surfaces Processes and Landforms 18: 4361.

Parker G. 1991. Selective sorting and abrasion of river gravel. I: theory. Journal of Hydraulic Engineering 117: 131147.

Parker G, Wilcock PR, Paola C, Dietrich WE, Pitlick J. 2007. Physical basis for quasi universal relations describing bankfull hydraulic 
geometry of single thread gravel bed rivers. Journal of Geophysical Research 112 F04005, https://doi.org/10.1029/2006JF000549.

Rice S. 1994. Towards a model of changes in bed material texture at the drainage basin scale. In Process Models and Theoretical Geomor phology, Kirkby MJ (ed). John Wiley and Sons; 159172.

Rice S. 1995. The Spatial Variation and Routine Sampling of Spawning Gravels in small Coastal Streams. Ministry of Forests Research Program Province of British Columbia: Canada.

Rigon E, Comiti F, Lenzi MA. 2012. Large wood storage in streams of the Eastern Italian Alps and the relevance of hillslope processes. Water Resource Research 48: 118.

Schumm SA. 1977. The Fluvial System. Wiley: New York.

Schumm SA, Litchy RW. 1965. Time, space, and causality in geomor phology. American Journal of Science 263: 110119.

Slaymaker O. 1993. The sediment budget of the Lillooet River basin. British Colunbia Physical Geography 14: 304320.

Sutherland Brown A. 1968. Geology of the Queen Charlotte Islands, British Columbia. British Columbia Department of Mines and Petro leum Resources, Bulletin No. 54.

Whiting PJ, Bradley JB. 1993. A process based classification system for headwater streams. Earth Surface Processes and Landforms 18: 603612.

Wilford DJ, Schwab JW. 1982. Soil mass movements in the Rennell Sound area, Queen Charlotte Islands, British Columbia. In Hydrolog ical Processes of Forested Areas, Proceeding of the Canadian Hydro logical Symposium. National Research Council: Fredericton, New Brunswick; 521541.

Williams GDV. 1968. Climate of the Queen Charlotte Islands. In Flora of the Queen Charlotte Islands, Calder JA, Taylor RL (eds). Canadian Department of Agriculture, Plant Research Institute, Ottawa: Ontario; 1649.

Wohl E. 2004. Limits of downstream hydraulic geometry. Geology 32: 897900.

Wohl E. 2017. Connectivity in rivers. Progress in Physical Geography 41: 345362 .

Wohl E. 2018. Geomorphic context in rivers. Progress in Physical Geography 42: 1 17. https://doi.org/10.1177/0309133318776488.

\section{Supporting Information}

Additional supporting information may be found online in the Supporting Information section at the end of the article.

Figure S1: Example regression tree for predicting modeled re siduals of width, depth and slope. A mean value is assigned to each quadrant in the scatterplot.
Figure S2: Histograms of measured residuals of width, depth and slope models subtracted from predicted (BRT) residuals.

Figure S3: Partial dependence plots of the width for the Ferrer Boix, Finnegan Boulder, Finnegan Gravel and Parker width models showing the fitted function for each covariate.

Figure S4: Perspective plot showing predicted values for two most important interactions between predictors in the BRT models for the Ferrer Boix, Finnegan Boulder, Finnegan Gravel and Parker width models.

Figure S5: Partial dependence plots of depth for Finnegan Gravel, Finnegan Boulder and Parker depth models showing the fitted function for each covariate.

Figure S6: Perspective plot showing predicted values for two most important interactions between predictors in the BRT models for the Finnegan Boulder, Finnegan Gravel and Parker depth models.

Figure S7: Partial dependence plots of slope for the Parker slope model showing the fitted function for each covariate.

Figure S8: Perspective plot showing predicted values for two most important interactions between predictors in the BRT model for the Parker slope model.

Figure S9: Downstream patterns of bed shear stress ( $a$ and $b$ ) and dimensionless shear stress associated to $\mathrm{D}_{95}$ (c and d) for Riley and Gregory creeks. Best fit lines are shown for comparison.

Figure S10: Measured width shown with predicted width under different scenarios of bankfull to critical shear stress ratios in (a) Riley and (b) Gregory creeks.

Table SI. Study dataset and data acquisition methods

Table SII. Summary of results derived from the BRT models fit to the width and depth model residuals. Mean deviances are given for the model, model residuals, and cross validated model residuals (i.e. the residuals within the BRT model fitting and not the predicted residuals of the width, depth and slope models). Deviance gives the cross validated proportion of the total deviance explained, while CV gives cross validated corre lation coefficient (both derived from the validation folds). Stan dard errors are given in parentheses.

Table SIII. Summary of predictions made from the four width and depth models. The subscripts "raw" and "cal" denote a model prediction before and after applying the appropriate BRT calibration, respectively. 